\title{
Analysis of wintertime atmospheric moisture transport and its variability over southern Europe in the NCEP Reanalyses
}

\author{
Jesús Fernández ${ }^{1, *}$, Jon Sáenz ${ }^{1}$, Eduardo Zorita ${ }^{2}$ \\ ${ }^{1}$ Depto. Física Aplicada II, Universidad del País Vasco, Apdo. 644, 48080 Bilbao, Spain \\ ${ }^{2}$ GKSS Research Centre, Institute of Hydrophysics, 21502 Geesthacht, Germany
}

\begin{abstract}
A common analysis of instrumental monthly precipitation records and $6 \mathrm{~h}$ meteorological Reanalysis from the National Centers for Environmental Prediction (NCEP) was performed to diagnose the main modes of tropospheric, vertically integrated moisture transport over the Mediterranean basin and southern Europe. The moisture transport and its variability at each grid point and at the boundaries of the domain were quantified. Quantities such as the standard deviation of filtered geopotential height, one-point correlation maps and $Z_{300}-Z_{500}$ and $Z_{500}-Z_{700}$ thicknesses, related to the intensity and typical paths of baroclinic disturbances, were also computed to help in the interpretation of the results. It is clear that the leading mode of Mediterranean precipitation has its roots in the dynamics of the Atlantic storm track and the associated moisture transports. The second mode represents the internal redistribution of moisture inside the Mediterranean basin. Moisture is supplied to the atmosphere in the western Mediterranean, and this moisture is transported and precipitates over the eastern Mediterranean (mainly Turkey and Greece). Finally, the third mode depends on the role of European topography as a blocking factor for westerly moisture transport advected from the North Atlantic region.
\end{abstract}

KEY WORDS: Mediterranean · Southern Europe · Precipitation · Variability · Winter · Moisture

\section{INTRODUCTION}

The regions that surround the Mediterranean Sea frequently suffer from droughts, which may cause water shortages and disrupt agricultural and industrial activities, such as hydroelectric power generation. During a typical year, rain occurs most frequently during the winter months over most of the land area surrounding the Mediterranean, mainly in the southern and eastern parts. In general, there exists a clear deficit of water during the summer months, when only sparse storms and convective systems produce rainfall (Palutikof et al. 1994, Rodwell \& Hoskins 1996, Rodríguez-Puebla et al. 1998, Trigo et al. 1999). Fig. 1 shows the fraction of precipitation during each season (DJF, MAM, JJA, SON) in a random selection of the sites used in this study coming from the Global Histor- ical Climatology Network (GHCN) data set described in the next sections.

In our opinion there are several long-term goals that justify an analysis of the atmospheric water cycle in this area. First, such an analysis contributes to the understanding of the processes responsible for the low-frequency variability of precipitation and therefore the occurrence of multiyear drought periods, which is still quite limited.

Furthermore, such an analysis can contribute to an explanation of the reduction in precipitation that has taken place during the last decades. From the analysis of observed data alone, some researchers (Trigo et al. 1999, Quadrelli et al. 2001, and references therein) have identified a decreasing trend in the amount of rainfall over several areas in the Mediterranean basin. However, other studies (Kutiel et al. 1996) do not 


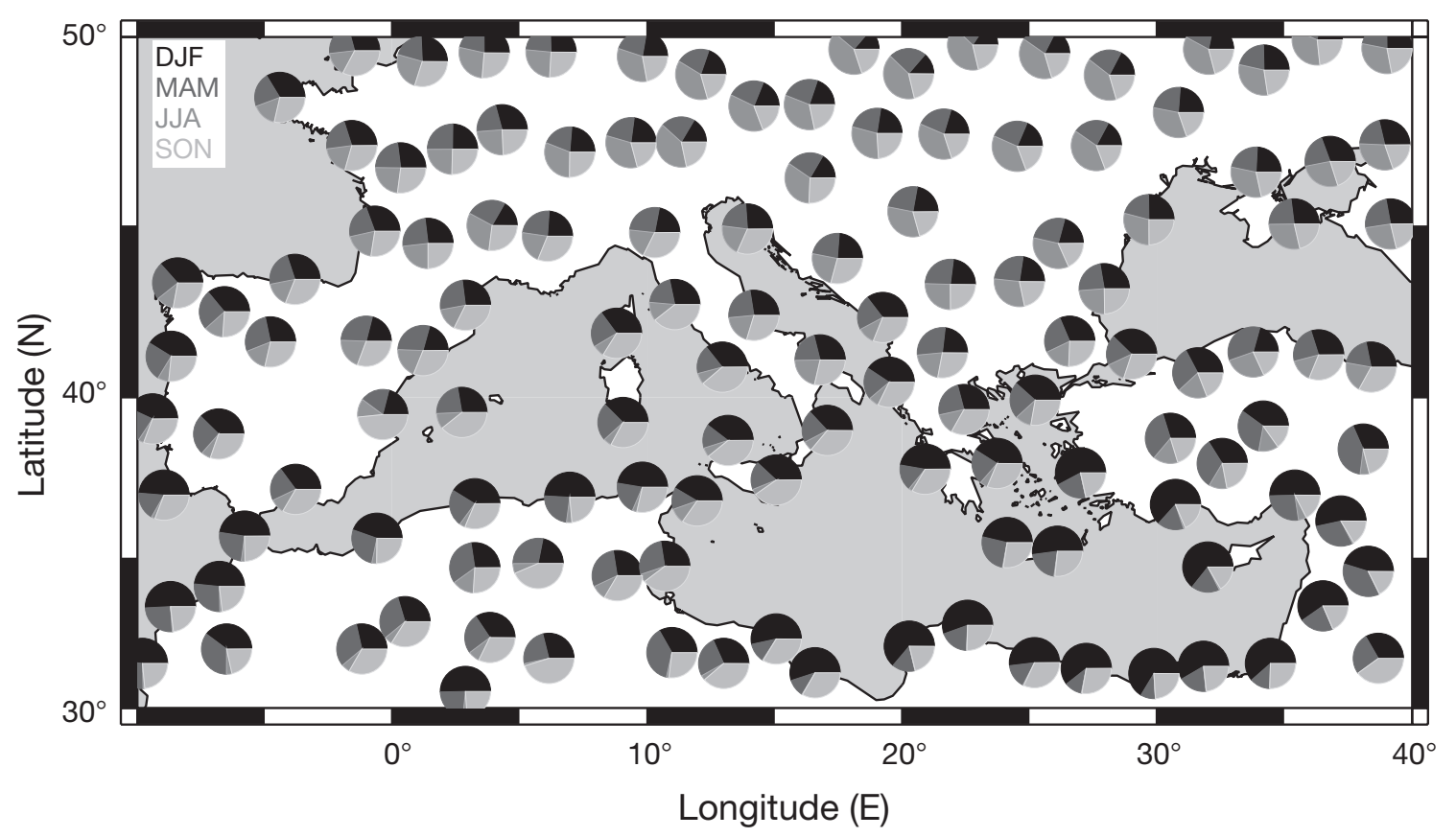

Fig. 1. Seasonal distribution of precipitation over several Global Historical Climatology Network (GHCN) sites randomly selected in the study area

report significant basin-wide trends of rainfall. Therefore, the results are still controversial. Over the Iberian Peninsula, for instance, a recent paper (GonzálezRouco et al. 2001) showed that the seasonal trends are different and that, in several cases, the annual trends may be due to inhomogeneities in the original data.

Regardless, the danger of an increasing desiccation in the Mediterranean in the future should be considered. Some previous studies using general circulation model (GCM) results (Palutikof et al. 1994) indicate that, due to an enhanced greenhouse effect, there could be a reduction in moisture availability, measured in terms of precipitation minus potential evapotranspiration, over the whole of the Mediterranean basin in the near future. Other GCM studies predict a reduction of the storm track activity over the Mediterranean region due to anthropogenic greenhouse forcing (Hulme et al. 1999, Ulbrich \& Cristoph 1999). Other studies (González-Rouco et al. 2000) predict an increase in the advection of oceanic moisture and an increase in precipitation for the Iberian Peninsula due to an enhanced greenhouse effect plus aerosol scenario. An improved understanding of moisture transports over southern Europe will allow a better picture of the hydrological cycle in the area and reduce the indeterminations under enhanced greenhouse conditions.

It is generally accepted that an important contribution to winter rainfall in southern Europe is due to Atlantic synoptic systems leaving the Atlantic storm track and entering southern Europe and the Mediter- ranean basin (Trigo et al. 1999, 2000). Thus, a change in the structure of the Atlantic storm track leads to a decrease in rainfall over the Mediterranean (Trigo et al. 2000). This is the reason for the well-known relationship of the North Atlantic Oscillation (NAO) with winter precipitation over wide areas of the Mediterranean (Hurrell 1995, Hurrell \& van Loon 1997, Rodó et al. 1997, González-Rouco et al. 2000, Quadrelli et al. 2001, Mariotti et al. 2002). Changes in the NAO and other atmospheric large-scale features appear simultaneously with changes in the latitudinal position of the tail of the Atlantic storm track (Rogers 1990, 1997), and this affects the way Atlantic perturbations affect precipitation over some Mediterranean areas. When the tail of the Atlantic storm track migrates to the south (negative NAO phases), the Atlantic perturbations affect the Mediterranean basin during their eastward propagation. There are also simultaneous changes in the vertically integrated moisture transport on a hemispheric scale during different phases of the NAO (Hurrell 1995). The aim of this paper is to extend this research with an analysis of other modes of variability different to the NAO that can be detected in southern Europe.

However, subsynoptic and mesoscale Mediterranean systems play an important role in Mediterranean rainfall, and it seems difficult to assess their role by using the coarse-resolution National Center for Environmental Prediction (NCEP/NCAR) Reanalysis data. Surface processes play an important role in the gener- 
ation of Mediterranean cyclones through the release of latent heat and moisture. The topography of the Mediterranean basin is very complex (see Fig. 11), and the regional landscape acts to produce orographic and thermal forcing over the observed structure of weather systems and regional circulations. Currently, we cannot quantitatively assess the impact on the results shown below of the inability to track subsynoptic-scale systems at the current resolution of the Reanalysis data. However, there is a great degree of consistency between results derived from observed precipitation (which includes all kinds of precipitation) and moisture transports. As both fields are derived from independent sources, we can be confident that the main characteristics of the moisture transports are correct.

During an extensive study of Mediterranean cyclones, Trigo et al. (1999) identified 3 important features of winter Mediterranean cyclones. (1) The Gulf of Genoa is one of the main sources of Mediterranean cyclones during the whole of the year. (2) The Gulf of Biscay and central Iberia are the main paths of entry for winter Atlantic cyclones into the Mediterranean. (3) During winter, the Gulf of Genoa cyclones propagate across Italy down to the Greek and Albanian coasts.

Some studies have already identified different mechanisms in the generation of Mediterranean cyclones. According to the analysis by Alpert et al. $(1990 a, b)$, the sea thermal effect is very important over the eastern Mediterranean, whereas lee cyclogenesis is a more important effect during winter in the Gulf of Genoa cyclones (Alpert et al. 1990a). The different mechanisms in western and eastern Mediterranean rainfall have also been identified in some signatures of observational data; for example, droughts appear simultaneously at several stations in Portugal, but there is a lower spatial coherence of droughts in the eastern Mediterranean (Kutiel et al. 1996). Patterns of several atmospheric variables affect the western and eastern areas of the Mediterranean basin in different ways (Corte-Real et al. 1995, Reddaway \& Bigg 1996, Zhang et al. 1997, Eshel \& Farrell 2000, Ribera et al. 2000, and references therein).

Several papers analyze the climatology of synopticscale systems over the Mediterranean (Alpert et al. 1990a,b, Trigo et al. 1999). Other papers describe the averaged geopotential height fields relevant for the main modes of Mediterranean and European precipitation (Quadrelli et al. 2001). The climatology of moisture transports, precipitation, evaporation and fresh water input into the Mediterranean has been reported by Mariotti et al. (2002). They also analyze the impact of the NAO in the freshwater flux into the Mediterranean.

However, we are not aware of any work that analyzes in detail the variability of moisture transports over the whole area, including both the western and the eastern halves of southern Europe. The explicit analysis of the moisture transports and the sources (evaporation) and sinks (rainfall) of atmospheric humidity proved to be fruitful in the analysis of the relative role of external (Atlantic weather systems) and internal (Mediterranean cyclogenesis through surface processes) factors in the variability of precipitation over the whole Mediterranean basin, and it complements the information obtained from the analysis of the time-averaged geopotential heights alone. To properly assess these factors, the area of study has to consider the moisture influx from the Atlantic, thus extending the area covered by Alpert et al. $(1990 a, b)$ by $10^{\circ}$ of longitude to the west.

The computation of moisture balances from the Reanalysis data is not very precise, and there are several potential sources of error:

(1) The Reanalysis data are in fact analyzed, and the observations are merged with results from a GCM. Therefore, they are not pure observations; instead, they stem from a 4-dimensional data-assimilation scheme. This may be an advantage over in situ sounding data on the synoptic scale. However, the model used in the data-assimilation scheme may have some biases which make the use of Reanalysis data not very useful for detailed moisture balances (Trenberth \& Guillemot 1995). It is very important that the moisture data have very fine vertical and horizontal resolutions to achieve precise results, especially over small and intermediate catchment areas (Gutowski et al. 1997, Berbery \& Rasmusson 1999) and over areas with steep orography or irregularly distributed water areas (Berbery et al. 1996, Trenberth \& Guillemot 1998), such as the Mediterranean basin. However, the lack of a detailed network of tropospheric soundings over the area makes the use of the Reanalysis data necessary.

(2) The resolution of the Reanalysis data is not very high, and this can cause serious difficulties in an area like the Mediterranean, where the steep topography plays a major role in a myriad of local and regional features of climate.

(3) The use of pressure data in the vertical integral of the moisture transport produces some errors due to the interpolation from the original sigma surfaces to the pressure levels. This can be a problem if we consider that we have used the only publicly available vertical levels in the pressure-level $6 \mathrm{~h}$ specific humidity data (Higgins et al. 1996, Mo \& Higgins 1996, Trenberth 1998, 1999, Trenberth \& Guillemot 1998, Berbery \& Rasmusson 1999). However, according to results by Berbery \& Rasmusson (1999), we can expect that the errors derived from the coarse horizontal and vertical resolutions surpass the ones due to the use of pressure levels instead of sigma levels in the vertical integral. In 
any case, the interpolation errors are bigger in areas close to the tropics than over mid-latitudes due to the lack of a correct representation of the divergent component of the wind (Trenberth \& Guillemot 1995, 1998, Trenberth et al. 2001).

(4) Interpolation errors affect mainly the divergence of the transports and not so severely the transports themselves (Trenberth \& Guillemot 1995). Therefore, we will basically make use of vertically integrated moisture transports and the NCEP's original evaporation field instead of the divergence of the vertically integrated transports. No attempt is made to quantitatively balance the vertically integrated moisturetransport divergences and the evaporation and precipitation fields from the model. The basis of this paper will be observed precipitation fields, which are the most important factors in the spatial and temporal variability of the evapotranspiration-precipitation moisture budget (Trenberth \& Guillemot 1995).

These interpolation errors tend to be systematic (Trenberth \& Guillemot 1995). Therefore, we can expect that regression analysis cuts them to a minimum in the final results shown in the next sections. Whereas some biases may exist in the vertically integrated moisture transports, our specific focus is on the co-variability of precipitation with other variables, thus removing systematic errors. Consequently, it is expected that these biases will have a minor impact on the final results. Despite these potential errors, this study can be useful since it makes use of a comprehensive and homogeneous data set, as the Reanalysis data. This approach can yield guidelines for future analyses with currently unavailable improved data sets with much more detailed horizontal and vertical resolutions. This paper can be considered a first-order approximation to a problem that should be addressed and reevaluated in the near future with the use of a very high resolution data set after a regional Reanalysis is performed as a major effort by the climatological community.

\section{DATA}

The latitude-longitude box selected in this study is shown in Fig. 1. It extends in longitude from $10^{\circ} \mathrm{W}$ to $40^{\circ} \mathrm{E}$ and in latitude from 30 to $50^{\circ} \mathrm{N}$. It covers southern Europe. All of the data have been restricted to the Northern Hemisphere winter (DJF) on a monthly basis.

The paper analyzes basically precipitation data obtained from the Climate Research Unit (CRU), University of East Anglia (New et al. 2000). This is an overland monthly global data set with a $0.5^{\circ} \times 0.5^{\circ}$ spatial resolution which covers the period 1948-1996. In order to check the degree of confidence of the CRU data in the selected area, the results on the main modes of precipitation have also been compared with the ones from an alternative precipitation data set.

The second precipitation data set used is the GHCN precipitation data. We use it to confirm the results of the empirical orthogonal function (EOF) analysis derived from the CRU data set. The GHCN is a worldwide collection of instrumental records from 7533 stations collected and quality-controlled by the Carbon Dioxide Information Analysis Center (CDIAC), the National Climatic Data Center (NCDC), and the World Meteorological Organization (WMO). It is freely available and provides monthly values in a time range that is highly variable depending on the station, although no data are available after 1990. A total of 467 stations are in the box $10^{\circ} \mathrm{W}-40^{\circ} \mathrm{E}, 30-50^{\circ} \mathrm{N}$. The high number of missing values in this data set is somewhat problematic. To avoid the problem of the missing values, we use the GHCN data in a validation procedure for the accuracy of the CRU data. The 150 stations with the least missing values in the GHCN data set were selected. In these stations the missing values were replaced by the corresponding mean value before computing the GHCN-based EOFs. The spatial distribution of the 150 sites is shown in Fig. 11. The fraction of this data set that we use covers the period 1948-1990.

For the 3-dimensional, $6 \mathrm{~h}$ atmospheric fields such as sea-level pressure, geopotential height, wind speed and specific humidity at isobaric surfaces, the data files from the NCEP Reanalyses (Kalnay et al. 1996) were used, obtained from the NCEP WebServer. Some monthly fields, such as the latent heat flux (used in the estimation of the evaporation) and the vertical velocity $(\omega)$ at $850 \mathrm{hPa}$ and the geopotential height of the $500 \mathrm{hPa}$ surface, were also obtained from the NCEP Reanalyses WebServer.

The $6 \mathrm{~h}$ Reanalysis data were used to describe the atmospheric moisture transport and monthly standard deviation of filtered geopotential height anomalies corresponding to the principal components (PCs) derived from the observed precipitation fields (the CRU-based PCs). The NCEP Reanalysis monthly evaporation rate was used to confirm the role of evaporation in the moisture transport corresponding to the second EOF. Finally, the monthly geopotential height was used to compute the typical thicknesses during extreme (positive and negative) phases of the second EOF. $\omega$ was used to analyze the existence of ascendances or subsidences during typical values of the PCs.

In order to check whether the use of the Reanalysis data in the computation of the water transports is misleading in the analysis, we also used an homogenized data set of in situ sounding data, the Comprehensive Aerological Reference Data Set (CARDS) (Eskridge et al. 1996, Wallis 1998). Only 5 sites have enough 
available quality-controlled soundings in the area: 084950 - North Front, 107390-Stuttgart/Cannstatt, 162450-Pratica di Mare, 171300-Ankara/Central and 347310 - Rostov-on-Donu. For these sites, we also computed monthly vertically integrated moisture transports, and we compared the results with the ones obtained from the NCEP/NCAR Reanalysis.

\section{PCA COHERENT PRECIPITATION STRUCTURES}

Precipitation data sets were preprocessed to obtain the best results in the principal component analysis (PCA). As we are restricting ourselves to a single season (winter) and we are not interested in the seasonal variability of the data, the seasonal cycle was removed from each of the records by subtracting the long-term monthly average. After this deseasonalization, any existing linear trend was removed through a blind adjustment by means of a linear regression with the time coordinate at each grid point. Finally, the December, January and February monthly records were selected.

To find the main variability modes, the widely used PCA technique (Kutzbach 1967) was applied in the $\mathrm{S}$-mode to the covariance matrix of the de-seasonalized monthly precipitation data. The eigenvectors are presented as the correlation of the corresponding PC with the field series at each grid point. The degeneracy of the modes obtained was tested through the error bars of North et al. (1982). To test the stability of the eigenvectors, we performed a Monte Carlo test based on the temporal subsampling of the series. We computed the eigenvectors 50 times with series made up of 75 (half of the total record) randomly selected records. The accuracy of the master eigenvectors and the eigenvectors of each of the subsamples was quantified through the absolute value of the congruence coefficient (Richman \& Lamb 1985). These tests showed that the first 4 modes were clearly separated (see Fig. 2 for the leading 3 cases).

The PCA applied to the detrended precipitation data yielded the EOFs presented in Fig. 3. In this figure the 3 leading EOFs are plotted as the correlation of the corresponding $\mathrm{PC}$ with the precipitation series at each grid point. These 3 structures explain $49 \%$ of the total variance of the detrended field. The Monte Carlo test on the stability of the EOFs by means of random temporal subsampling also gives some confidence to the fourth EOF (figure not shown). However, this EOF has been removed from this study on the basis of Fig. 4, which shows the fraction of variance explained by each of the leading $3 \mathrm{PCs}$ at each grid point. The explained variance is localized in certain areas where it reaches values around $70 \%$. With the 3 leading EOFs explaining so much variance over disjoint areas of the selected region, there is no possibility for the fourth EOF to explain a significant amount of the variance of the field at any point. The highest grid point explained variance by this fourth PC is $43 \%$ over northern Algeria and is extremely reduced in spatial coverage (not shown). Therefore, it is a local feature of climate, and it would be better analyzed on a regional basis, as a wide-area study such as the current one probably does not represent it correctly. The orthogonality constraint is very strong for a fourth mode, particularly if it explains such a small fraction of variance. This is the reason why the fourth EOF has been disregarded in the current study.

To perform an additional check on the CRU EOFs, they were compared with those computed from the GHCN data. Fig. 5 shows the 3 leading PCs from both data sets. The first 2 PCs are interchanged. This is probably due to the low density of GHCN stations on

a)

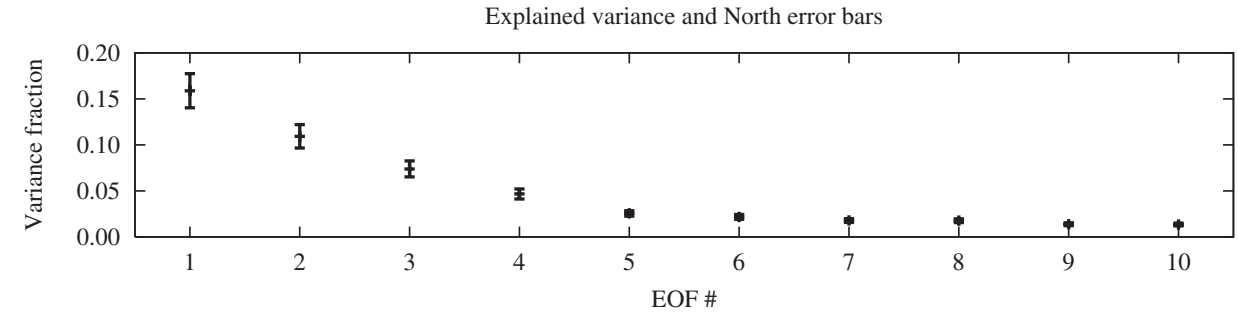

b)
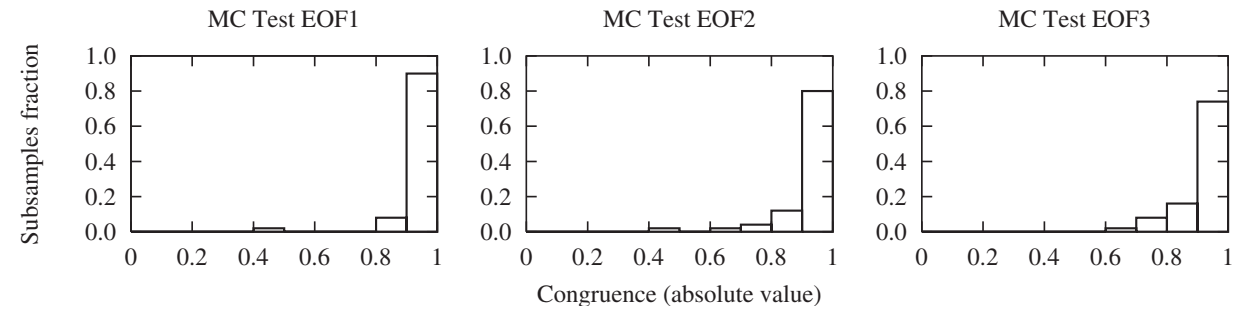

Fig. 2. Stability analysis for the leading CRU empirical orthogonal functions (EOFs). (a) Explained variance with North error bars. (b) Three leading EOFs random time subsampled EOF congruence absolute value 
the Iberian Peninsula ( 7 sites, see Fig. 11), which is the center of action of the first CRU-based PC, against over 20 sites covering Turkey and surrounding areas (center of action of the second CRU-based PC). The high correlation between the PCs from the different data sets means one can have quite high confidence in the CRU EOFs, apart from the non-overlapping North error bars and the stability of the Monte Carlo analysis already shown in Fig. 2. Finally, the 3 EOFs match well with recent results by Quadrelli et al. (2001), derived from a third alternative data set (CMAP) over the same region.

Returning to Fig. 3, we can see that the first EOF shows the typical precipitation fingerprint of the North Atlantic Oscillation, in which this major feature of the North Atlantic circulation controls the rainfall variability over the western Mediterranean. An increase in the precipitation over the western coasts of Italy and the
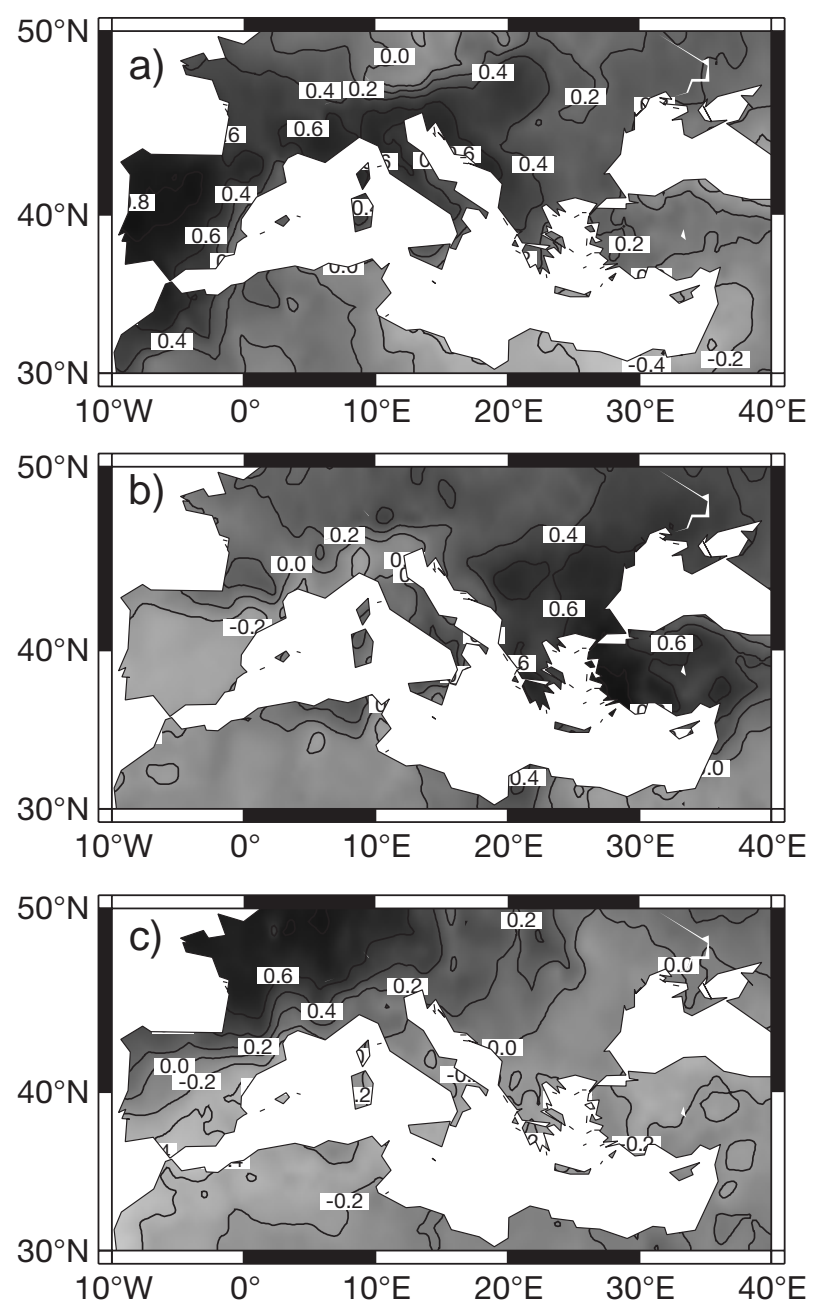

Fig. 3. From top to bottom: the 3 leading EOFs from the CRU precipitation field expressed as correlation of the corresponding principal component (PC) with the precipitation series at each grid point
Balkans is also associated with this mode. This main pattern explains $22 \%$ of the total precipitation variance. The correlation of the corresponding PC with the NAO index (Jones et al. 1997) is -0.52 (significant to $99.9 \%$ even after considering the autocorrelation of the series, as it has been computed with 141 monthly values).

The second pattern shows high loading factors over the eastern Mediterranean, reaching the highest values on the western coast of Turkey. This EOF explains $16 \%$ of the total variance.

The third EOF considered shows a north-south dipolar structure over the western half of southern Europe, with high loading factors over France. As for the first $\mathrm{EOF}$, the variability is likely to be controlled by processes that originate over the Atlantic Ocean. This will be discussed in detail in the following sections. The fraction of the total variance explained by this third
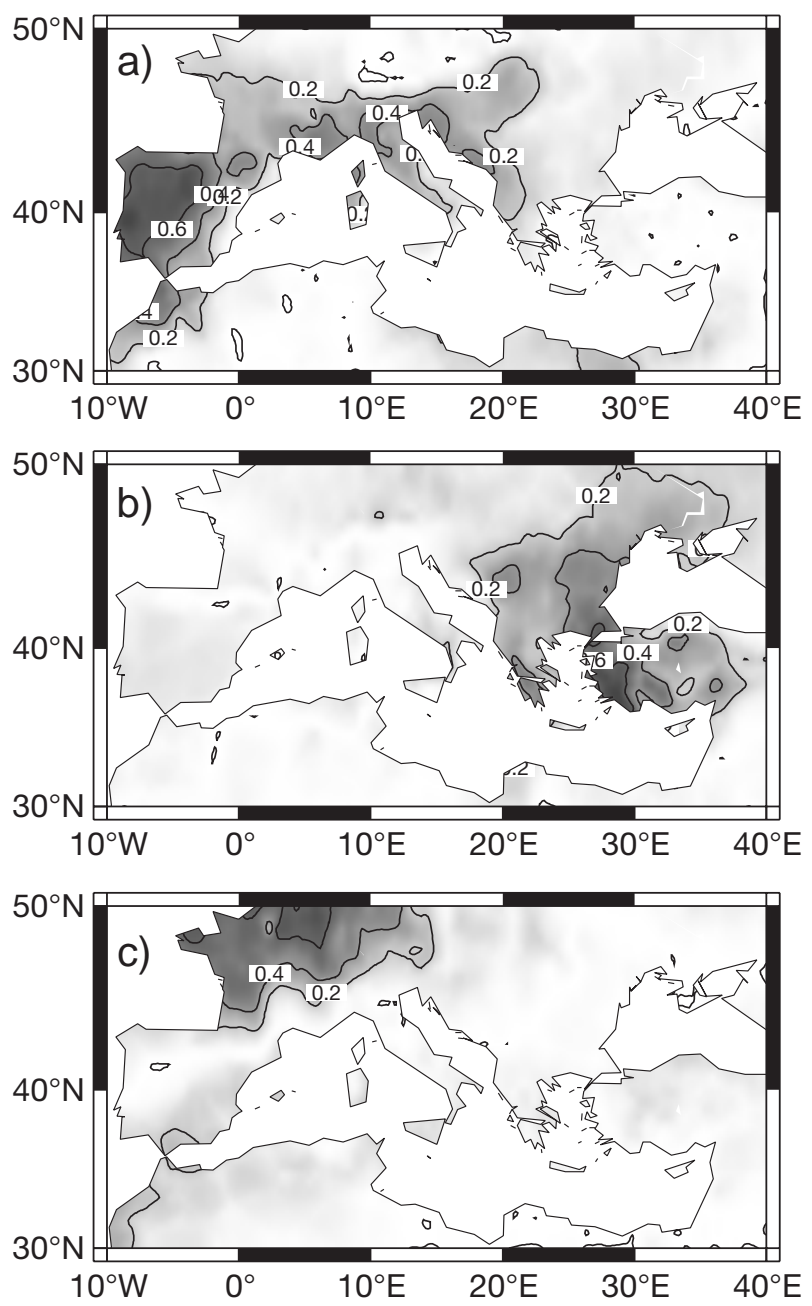

Fig. 4. From top to bottom: the variance fraction of the precipitation series explained by the 3 leading PCs 
a)

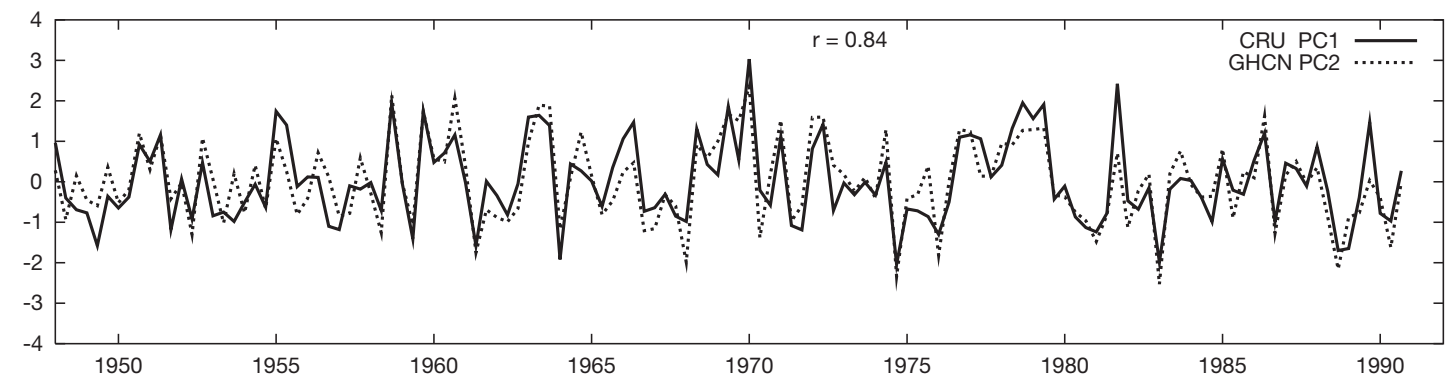

b)

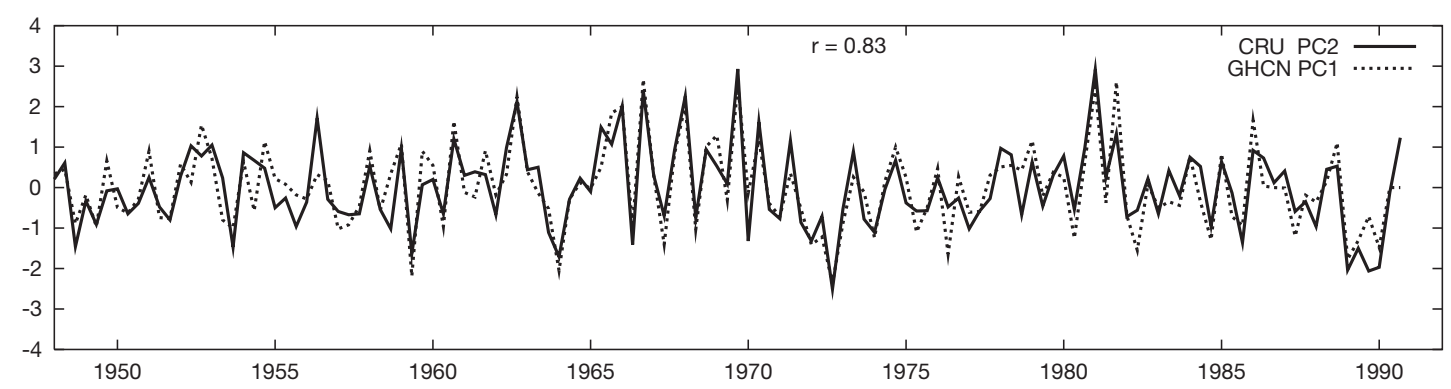

c)

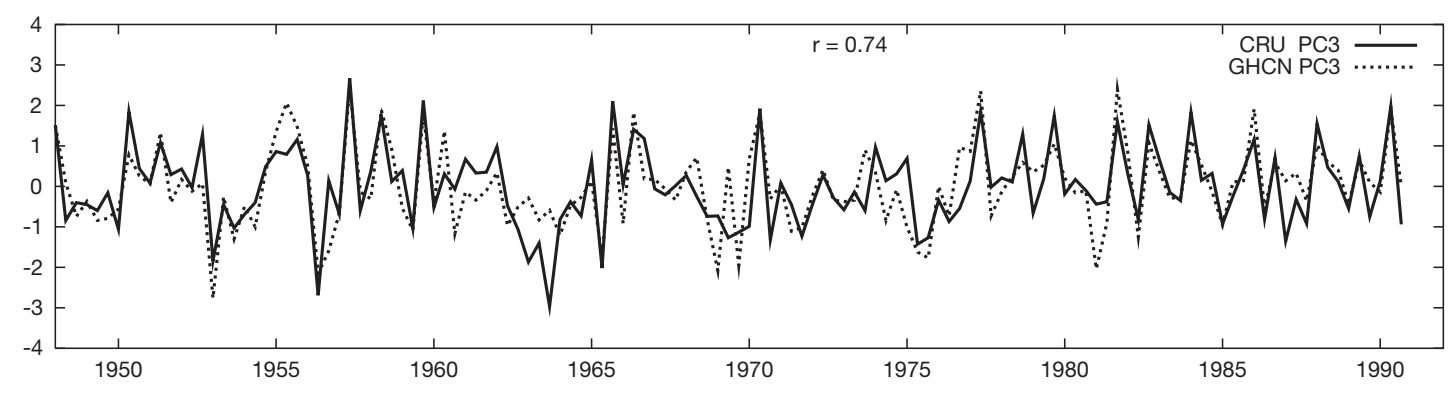

Fig. 5. Comparison of the 3 leading PCs from CRU and from GHCN. The first two are interchanged

mode is $11 \%$. Its PC correlates quite well with the East Atlantic Index as defined by Wallace \& Gutzler (1981). The East Atlantic pattern of atmospheric lowfrequency variability (Wallace \& Gutzler 1981, Nakamura et al. 1987) has a center over the British Isles and an opposite one elongated along the Mediterranean Sea influencing the inflow of humidity over northwestern Europe. The correlation coefficient $\mathrm{r}=0.58$ is significant to $99.9 \%$ even after considering the autocorrelations of the original series (significance test based on a Monte Carlo test).

\section{MOISTURE TRANSPORTS}

We computed the vertically integrated moisture transport from the NCEP's data interpolated to pressure surfaces:

$$
\vec{Q}=\frac{1}{g} \int_{p_{t}}^{p_{s}} q \vec{V} \mathrm{~d} p
$$

where $g$ is the acceleration of gravity, $p_{\mathrm{t}}$ the pressure at the top of the layers considered in this study (300 hPa), $p_{\text {s }}$ the surface pressure, $q$ the specific humidity and $\vec{V}$ the horizontal wind speed at isobaric surfaces. The vertical integral was roughly approximated by means of a Riemann sum at the following vertical levels $p_{\mathrm{i}}(\mathrm{hPa})=$ $1000,925,850,700,600,500,400,300$. Ideally, from a climatological perspective, considering that no longterm accumulation of precipitable water in the atmosphere exists, and that the moisture content at the highest layer considered in this paper $(300 \mathrm{hPa})$ and above is negligible, the relationship $\vec{\nabla} \times \vec{Q}=E-P$ should hold, where $E$ is the evaporation and $P$ is the precipitation field. However, because of the reasons mentioned in Section 1, we only use this balance equation in a qualitative manner, to show the match of the main sources and sinks of humidity in the basin derived from $\vec{Q}$ with the ones shown by the original NCEP's evaporation field in Fig. 12. We are interested in the moisture fluxes (vertically integrated through the troposphere as described above) crossing the boundaries of the selected Mediterranean domain. These fluxes allow us to show the main paths followed by the atmospheric humidity to enter and exit the 

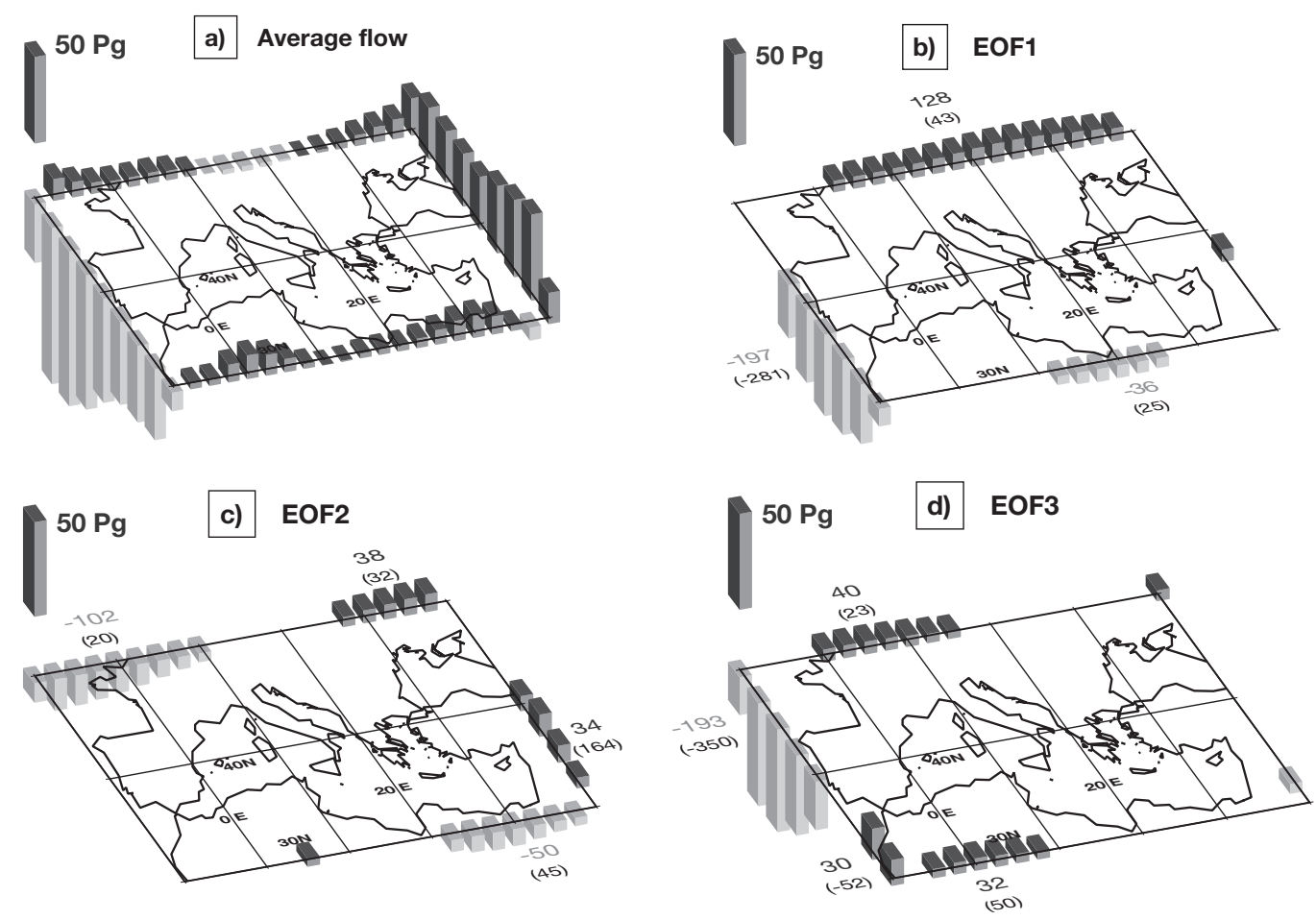

Fig. 6. (a) Average moisture flux through the boundaries according to NCEP data (in Pg mo ${ }^{-1}$ ). (b-d) Regression of the precipitation PCs over the boundary moisture flux. Only those regression values that are $99 \%$ significant according to a $t$-test are shown. Light (dark) shading indicates inflow (outflow). The numbers show the flux accumulated through each section. The numbers in brackets show average flow accumulated through the same section

domain during extreme phases of the PCs. To analyze these fluxes, we defined unitary vectors at each grid point of the boundaries in the Reanalysis latitudelongitude grid. The fluxes were computed by means of the expression $F_{\mathrm{i}}=l_{\mathrm{i}} \vec{Q}_{\mathrm{i}} \times \hat{u}_{\mathrm{i}}$, where $\vec{Q}_{\mathrm{i}}$ is the vertically integrated transport at each grid point, $\hat{u}_{i}$ the unitary vector exiting the domain at each of the grid points and $l_{\mathrm{i}}$ the horizontal length of the grid cell in a direction perpendicular to the corresponding unitary vector.

Regressions of the PCs over moisture transports and latent heat flux were calculated in order to analyze their behavior during prevailing situations of each mode. The regression results are expressed in the same units as the original field. The regression patterns obtained represent the anomalous field in a situation where the regressed $\mathrm{PC}=1$ and the remaining ones are set to zero. The average field must be added to obtain the full field in each of the $\mathrm{PC}_{\mathrm{i}}=1$ situations. As already mentioned in Section 1, we analyze the covariability between the observed precipitation PCs and the vertically integrated moisture transports. Therefore, the systematic errors induced in the vertical integral in pressure levels will be reduced in the regression analysis. The regressions over latent heat flux are displayed converted into evaporation, which can be compared in a straightforward manner with precipitation in $\mathrm{mm} \mathrm{d}^{-1}$.

For verification, we also computed the vertically integrated moisture transports from the CARDS in situ soundings described in Section 2. This time, for each sounding, we vertically integrated the transport by means of a trapezoidal rule from the surface to $300 \mathrm{hPa}$, interpolating linearly in the $\ln (p)$ variable. Only those soundings with at least 4 valid levels from surface to $300 \mathrm{hPa}$ were deemed valid. We have only considered as valid those months with at least $50 \%$ of the soundings available. In all cases, except when there is no significance in the correlation coefficients, the arrows at each site follow closely the values of the transports derived from the Reanalysis data at near points (figures not shown).

The main features of the moisture flux through the boundaries of the region according to the NCEP data are summarized in Fig. 6. The average flux through the boundary is shown in Fig. 6a. As the outflow is selected as positive flux, the negative values along the western boundary represent the inflow of humidity coming from the Atlantic Ocean. An average inflow of $494 \mathrm{Pg} \mathrm{mo}^{-1}$ crosses this boundary. The main outflow from the basin takes place through the eastern boundary. Both the northern and southern 


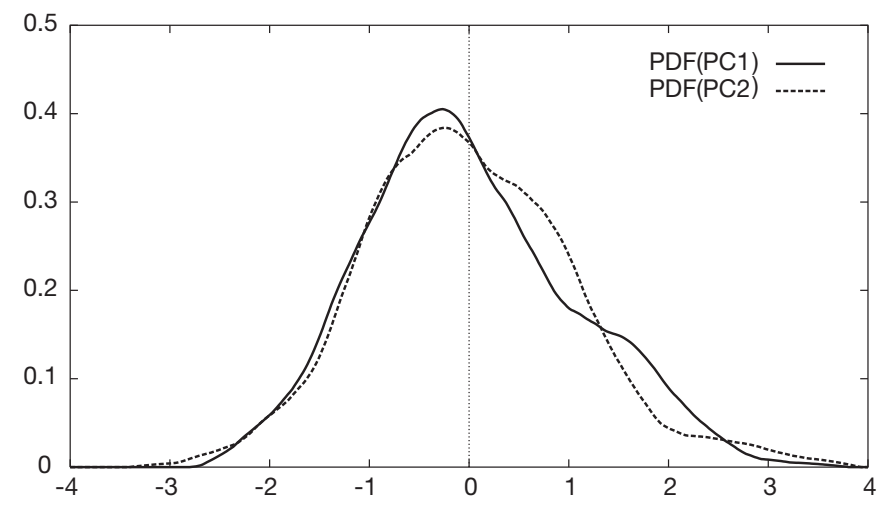

Fig. 7. Probability density functions (PDFs) associated with $\mathrm{PC}_{1}$ and $\mathrm{PC}_{2}$

boundaries, in a minor quantity, mainly export humidity. The only exceptions are section $12.5-22.5^{\circ} \mathrm{E}$ on the northern boundary with a very small inflow and a grid point on the southern boundary with humidity inflow from the Red Sea over the Suez Canal. On average, the basin is quite well balanced and presents only slightly more inflow than outflow, $15 \mathrm{Pg}$ $\mathrm{mo}^{-1}$. This is equivalent to a constant moisture deficit over the whole area of $0.05 \mathrm{~mm} \mathrm{~d}^{-1}$, which is quite a low value. However, it should be considered that this figure refers only to the atmospheric branch of the hydrological cycle, without taking into account surface runoff.
The regression of the first $\mathrm{PC}$ of precipitation on the moisture flux (Fig. 6b) shows 3 different sections where this regression is significant. The most important is an inflow of $197 \mathrm{Pg}$ through the western boundary. That means that in a situation with $\mathrm{PC}_{1}=1$ the inflow through this section $\left(281 \mathrm{Pg} \mathrm{mo}^{-1}\right)$ would be over $160 \%$ greater than the long-term mean. In such a situation the modest northern outflow (43 $\mathrm{Pg} \mathrm{mo}^{-1}$ ) would also experience an enhancement of $128 \mathrm{Pg}$ $\mathrm{mo}^{-1}$ (around 3 times the average value). Surprisingly, the outflow to Africa through the southern boundary is reversed during positive phases of this mode, resulting in a net inflow from Africa. This is a puzzling result, suggesting that the Sahel is exporting humidity to the Mediterranean over Libya. The interpretation of this result lies in the skewness of the corresponding PC (probability density function in Fig. 7). Fig. 6b-d show a regression analysis. As the variable involved in the regression $\left(\mathrm{PC}_{1}\right)$ is skewed, it tends to give more weight to negative phases. There is an increment of outflow during the negative and more frequent phases of the corresponding $\mathrm{PC}$, and it is this flux which appears as an input in the regression analysis, because it is multiplied by a negative factor $\left(\mathrm{PC}_{1}<0\right)$. There is zonally oriented vertically integrated transport over the southern boundary during positive phases of the PC according to the compositebased maps of $\vec{Q}$ (Fig. 8). Therefore, no export/import of humidity takes place through the boundary during

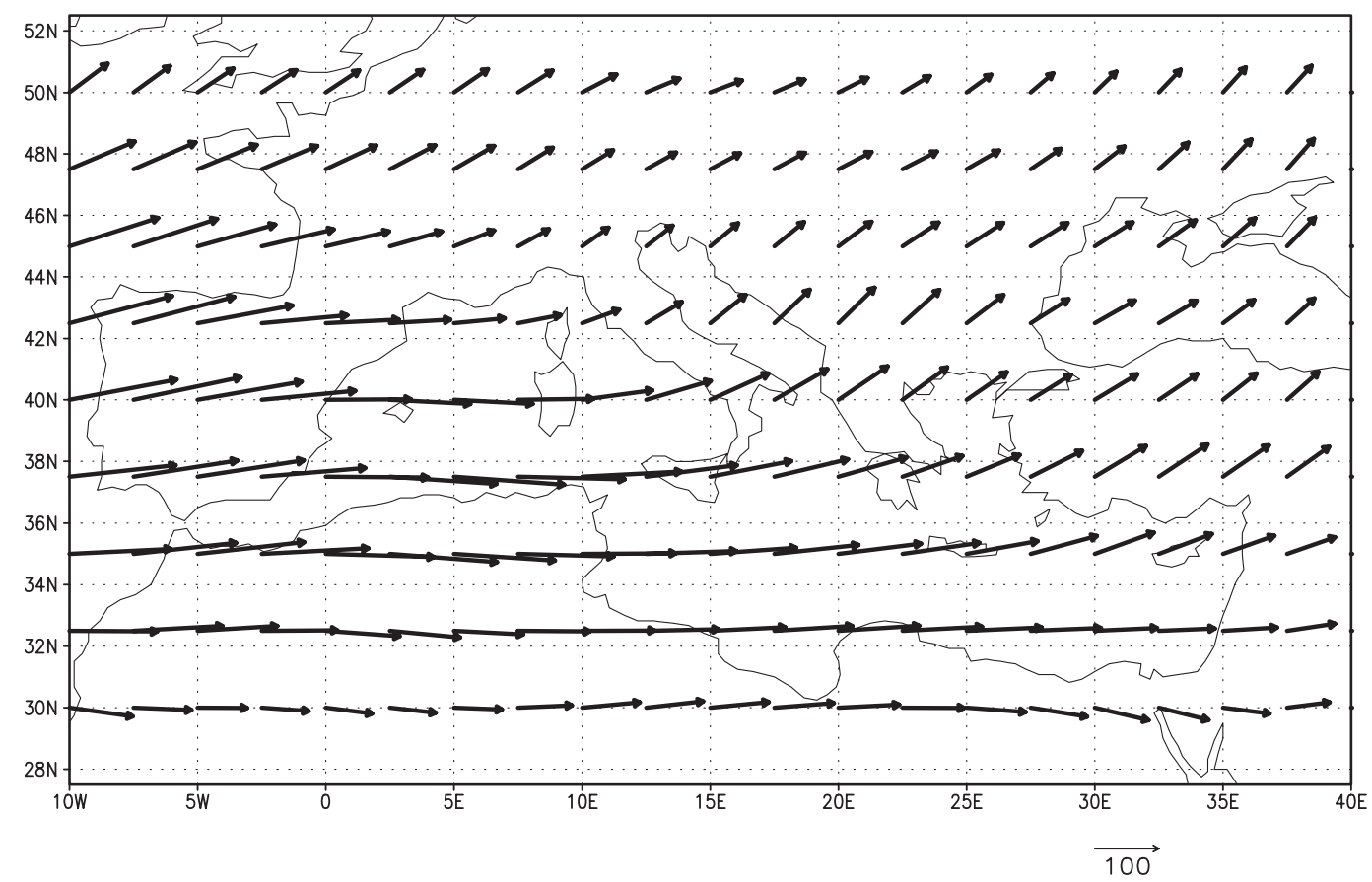

Fig. 8. Vertically integrated moisture transport during positive $\left(\mathrm{PC}_{1}>\sigma_{1}\right.$ ) phases (units: $\mathrm{kg} \mathrm{m}^{-1} \mathrm{~s}^{-1}$ ) 
these positive phases. Conversely, during (more frequent) negative phases of $\mathrm{PC}_{1}$ (Fig. 9), there is a clear export of humidity from the Mediterranean to northern Africa through the area $15-27.5^{\circ} \mathrm{E}$. This difference between positive and negative phases and the corresponding lack of linearity explains the puzzling result previously mentioned, as the regression analysis is not able to discriminate between positive and negative polarities of the PC (the objective function is quadratic and both phases have the same weight). In summary, positive phases of this mode are associated with a clear total import of moisture over the whole basin, with an overall net inflow of $98 \mathrm{Pg} \mathrm{mo}^{-1}$ (with $\mathrm{PC}_{1}=1$ ).

In a situation where $\mathrm{PC}_{2}=1$ (Fig. 6c) the outflow through the western side of the northern boundary is reversed and the one through the eastern side is enhanced. The flow through the eastern boundary is also slightly enhanced. Again, a reversal in the southern boundary induces an anomalous inflow from Africa. Here, the explanation is the same as it was in the case of $\mathrm{PC}_{1}$. Positive phases are associated with zonal moisture transports and, therefore, no import of humidity from northern Africa. Conversely, and according to composite-based maps, negative phases of $\mathrm{PC}_{2}$ show a clear export of moisture from the Mediterranean towards northern Africa through the area $22.5-35^{\circ} \mathrm{E}$, which explains the apparent inflow of humidity through the region in Fig. 6c. The total mois- ture balance during positive phases of this PC amounts to an inflow of $76 \mathrm{Pg} \mathrm{mo}^{-1}$.

The regression of the moisture flux through the boundaries for $\mathrm{PC}_{3}$ is shown in Fig. 6d. Its main characteristic is the $193 \mathrm{Pg}$ inflow through the western boundary that reinforces the value of $350 \mathrm{Pg}$ that, on the average, crosses the same section during $1 \mathrm{mo}$. The humidity comes through the northern side of this boundary and mainly precipitates over France, as can be observed on Fig. 3. Significant outflows also appear through the northern boundary off northern France. The outflow (during positive phases of $\mathrm{PC}_{3}$ ) through the western corner of the region reflects the fact that during those positive phases, there is a significantly lower amount of humidity entering the southern part of the domain through the western boundary (the average flow is negative and greater in absolute value than the anomalous flow). There is a weak outflow of humidity through the southern boundary due to the redistribution of humidity entering the domain through the northern boundary. As a whole, during positive phases of $\mathrm{PC}_{3}$, there exists a net inflow of $90 \mathrm{Pg} \mathrm{mo}^{-1}$.

The first and third modes are characterized by the influence of the Atlantic Ocean as the main source of humidity. This humidity crosses the whole Mediterranean region in the case of the first EOF (Fig. 10) explaining the highest precipitation variance. In the case of the third EOF this humidity enters the region through the northern part of the domain, and it is not

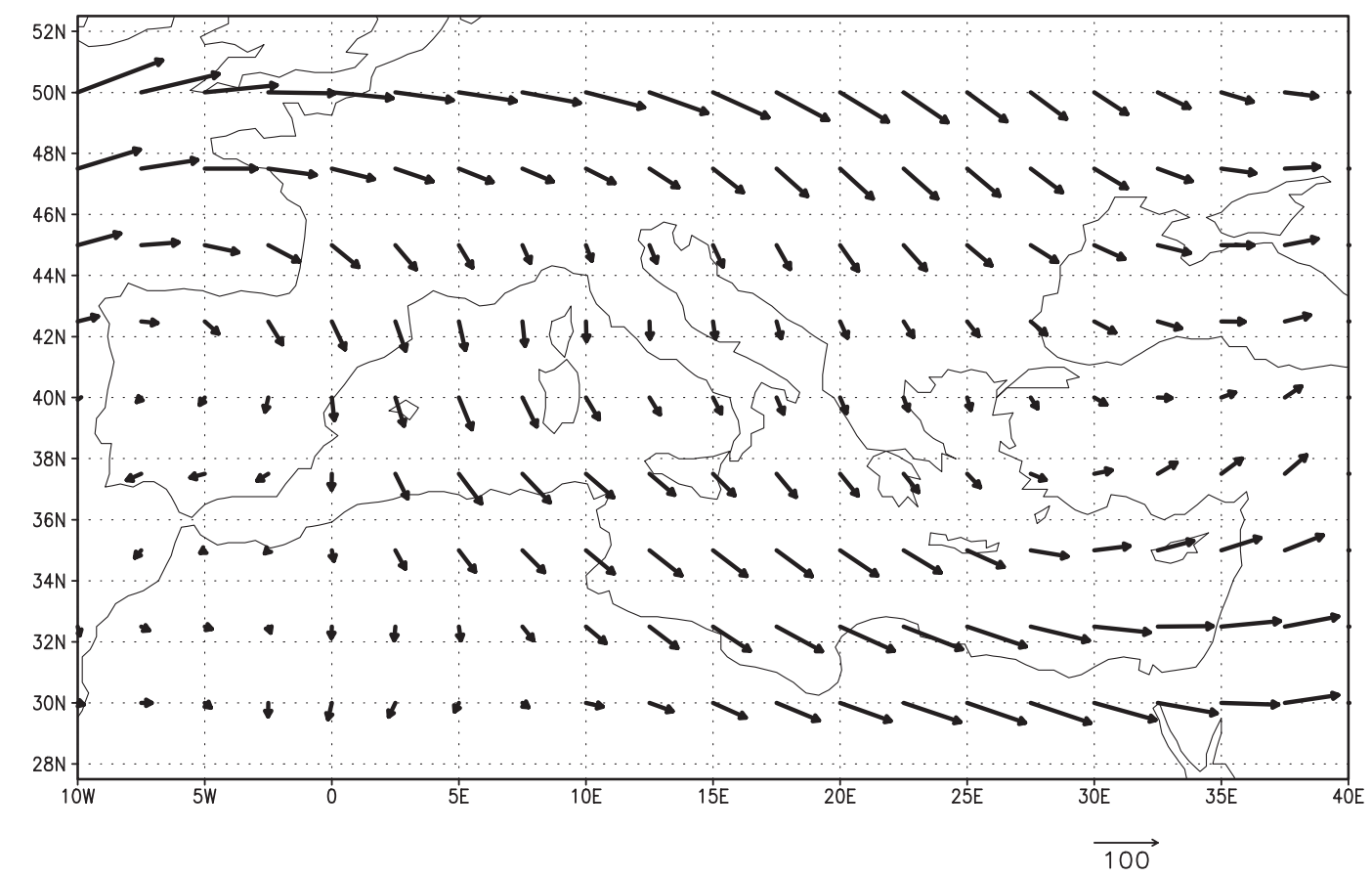

Fig. 9. Vertically integrated moisture transport during negative $\left(\mathrm{PC}_{1}<\sigma_{1}\right)$ phases (units: $\mathrm{kg} \mathrm{m}^{-1} \mathrm{~s}^{-1}$ ) 


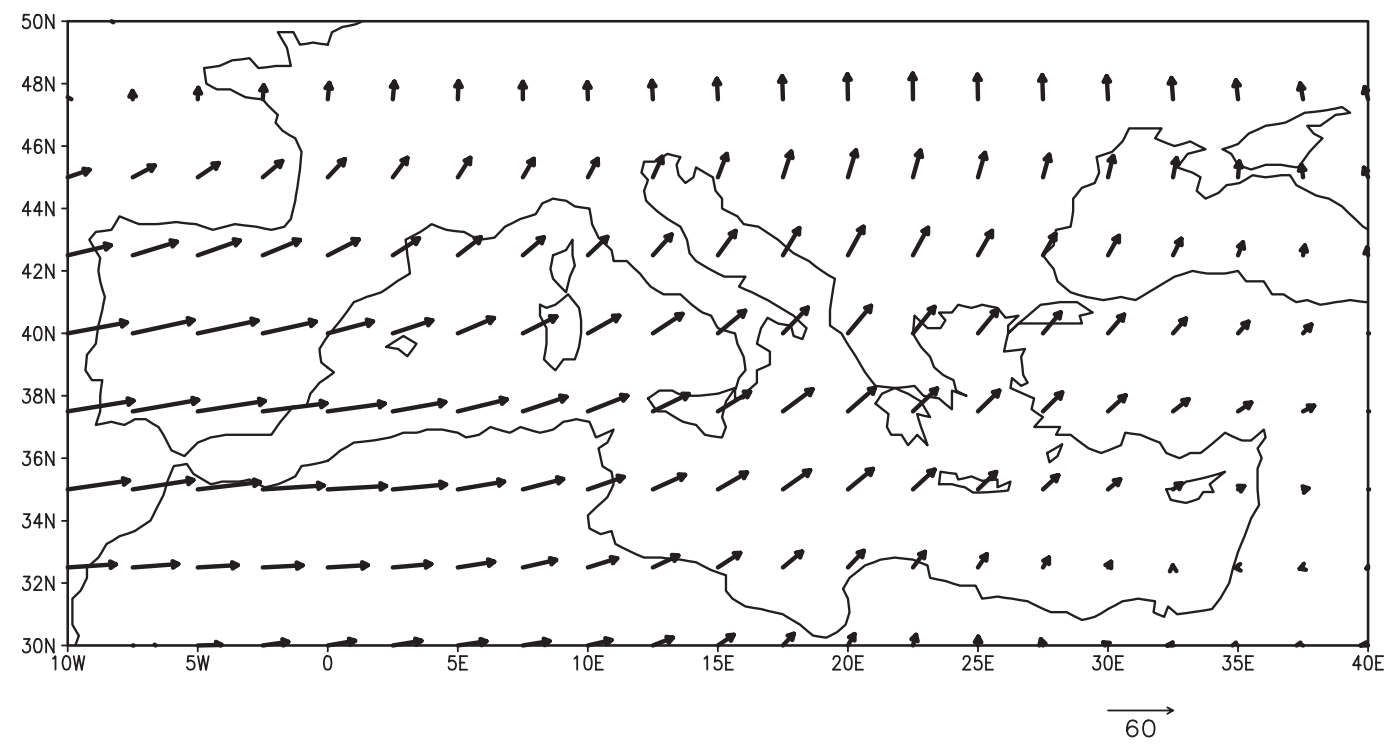

Fig. 10. $\mathrm{PC}_{1}$ regression over the total moisture flux at each grid point (units: $\mathrm{kg} \mathrm{m}^{-1} \mathrm{~s}^{-1}$ )

able to cross the whole of the continent due to the European topography. The influence of the oceanic humidity is restricted to a region over northern France and Central Europe due to orographically forced ascent, having a lesser influence for the Mediterranean climate. Fig. 11 shows again the third EOF (shaded), but this time the topography of the region is contoured in the background. The Pyrenees and the Alps set up a natural blocking barrier for the humidity flow from the Atlantic Ocean through this northern path. The ascent produces cooling, condensation and precipitation over the northern lee of the mountains.

From the point of view of a Mediterranean internal mode, $\mathrm{PC}_{2}$ is the most important one. This is the main precipitation mode in the Mediterranean region according to the GHCN data set. The average inflow from the Atlantic is not significantly altered in this mode, and the latter acts as a moisture redistribution mechanism inside the basin. The moisture transport over the region (Fig. 12) shows a cyclonic circulation centered at $20^{\circ} \mathrm{E}, 44^{\circ} \mathrm{N}$. This result is very similar to the one presented by Eshel \& Farrell (2000), although they used surface winds and geopotential height to analyze the eastern Mediterranean precipitation variability. Moisture enters through the western part of the northern boundary, sweeping the Mediterranean Sea and goes out through the eastern part of the northern boundary. High values of the divergence of this field (Fig. 12) are reached over the southern Bay of Biscay and the Mediterranean Sea, indicating that the Gulf of
Genoa and the western and central Mediterranean are the main sources of humidity (positive values of the divergence are related to evaporation).

To confirm the origin of the humidity in this mode, the NCEP surface latent heat fluxes were checked. Fig. 13 shows the latent heat flux regression with $\mathrm{PC}_{2}$ expressed as evaporation in $\mathrm{mm} \mathrm{d}^{-1}$. The centers of maximum evaporation are closely located over the areas with the highest divergence of the vertically integrated moisture transport. The maximum evaporation takes place in the Gulf of Genoa and south of Sicily. The center of divergent vertically integrated moisture transport over the southern Bay of Biscay (Fig. 12) is twice as intense as the Mediterranean centers, but this fact is not reflected in the evaporation rates, which are much more intense in the Mediter-

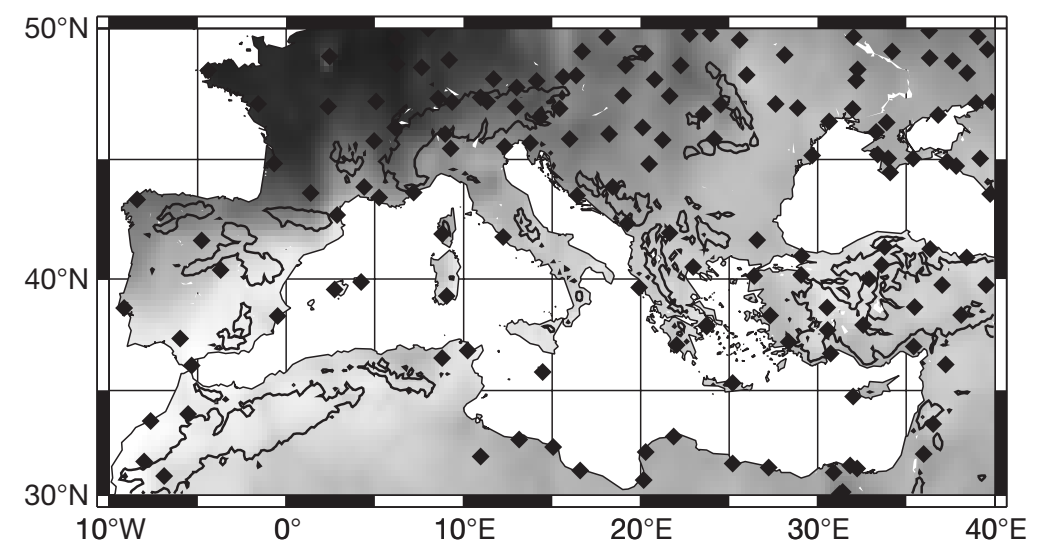

Fig. 11. Shaded: the third EOF as correlation of $\mathrm{PC}_{3}$ with the gridded time series (the same as Fig. 3c). Contours: orography; only the $1000 \mathrm{~m}$ contour is plotted. Diamonds: GHCN data set precipitation stations used 


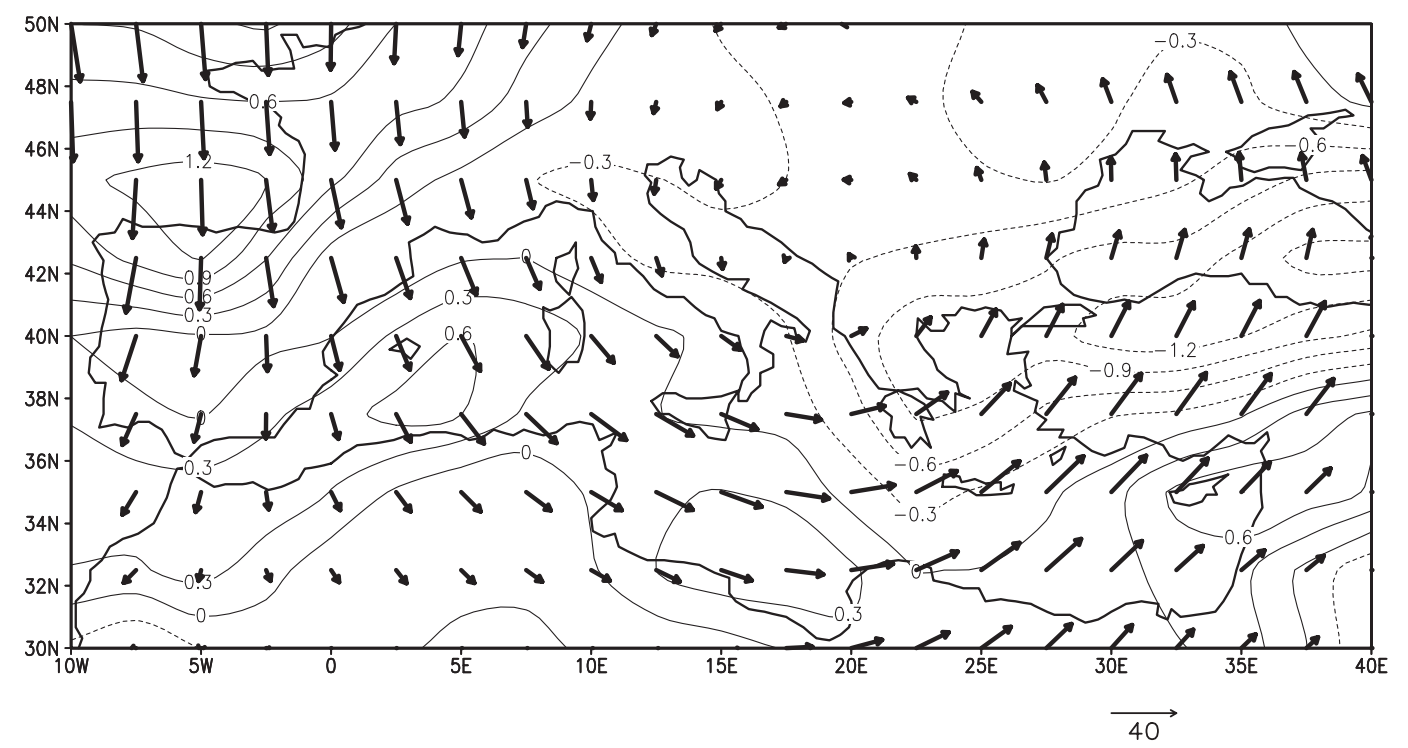

Fig. 12. $\mathrm{PC}_{2}$ regression over the total moisture flux at each grid point (units: $\mathrm{kg} \mathrm{m}^{-1} \mathrm{~s}^{-1}$ ). Contours: divergence of the (regressed) vertically integrated moisture transports (units: $\mathrm{mm} \mathrm{d}^{-1}$ )

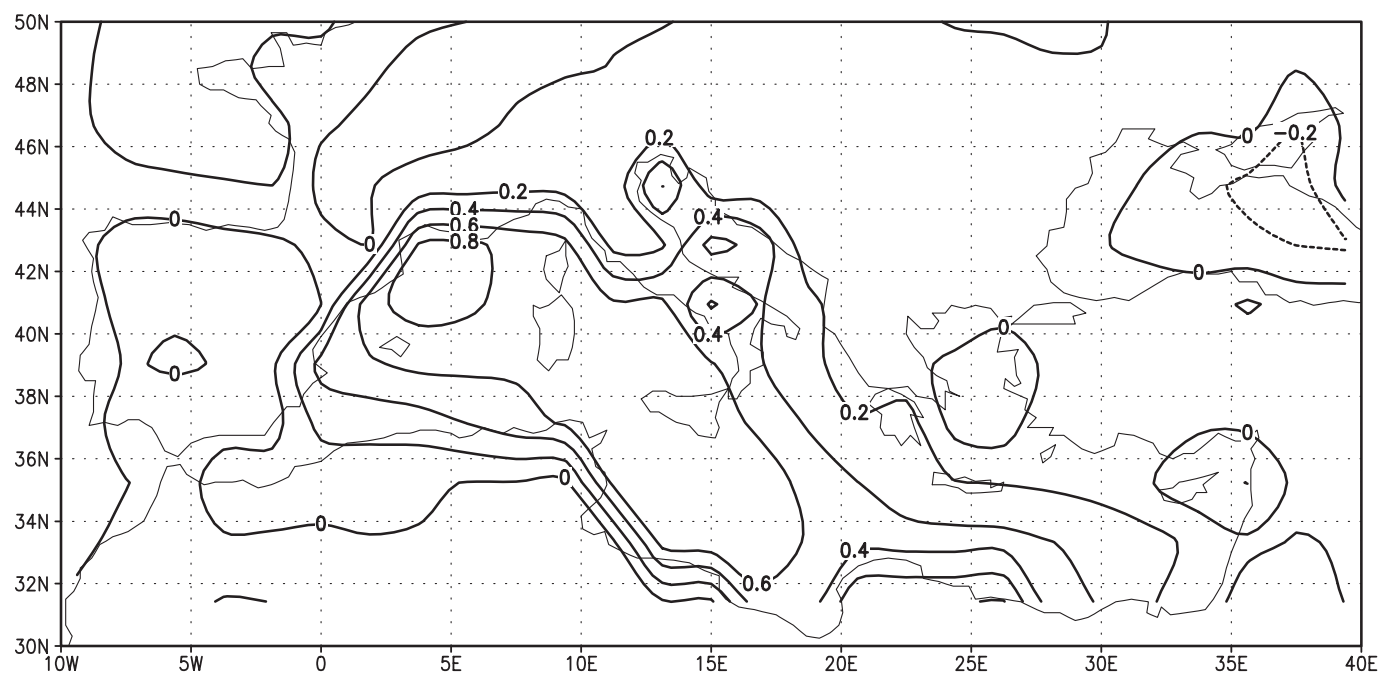

Fig. 13. Evaporation rate associated with $\mathrm{PC}_{2}$ (units: $\mathrm{mm} \mathrm{d}^{-1}$ )

ranean (Fig. 13). This disagreement could result from the steep topography close to the coast of the northern Iberian Peninsula, which affects the divergence of the moisture transport vectors through a numerical artifact related to the steep orography on the coast (Trenberth \& Guillemot 1995, 1998). Nonetheless, the evaporation rates over the Mediterranean Sea are related to the precipitation $\mathrm{PC}_{2}$, which reaches the highest loadings over the eastern Mediterranean. Therefore, it seems to be a mode highly localized on the region under consideration.

\section{SYNOPTIC-SCALE PERTURBATIONS}

The intensity of the synoptic activity was analyzed by means of a composite analysis of the geopotential height standard deviation during extreme phases of each precipitation PC. The paths of the synoptic disturbances were identified by means of one-point lagged correlation maps (Chang 1993, Ambrizzi et al. 1995) of filtered geopotential height of the $500 \mathrm{hPa}$ isobaric surface. The $Z_{500} 6 \mathrm{~h}$ field was filtered by means of a bandpass Lanczos filter (Duchon 1979), which removes the 
variability outside the 2.5 to $10 \mathrm{~d}$ periods, reducing the Gibbs effect.

For each of the PCs, subsets of months with the highest and the lowest values $\left( \pm 1 \mathrm{SD} \sigma_{\mathrm{i}}\right)$ of each $\mathrm{PC}_{\mathrm{i}}$ were selected. The composite and one-point lagged correlation maps below were constructed for each month independently, and the maps presented here show the ensemble-average of the individual months in the extreme ensembles.

The differences in the standard deviation of $Z_{500}$ for positive and negative phases of the PCs, $\sigma_{Z}\left(\mathrm{PC}_{\mathrm{i}}+\right)-$ $\sigma_{Z}\left(\mathrm{PC}_{\mathrm{i}^{-}}\right)$, are shown in Fig. 14. In this section the region shown is broader than in the rest of the paper, in order to appreciate the origin of the disturbances that come into play in the region of interest. A 2-tailed $t$-test on the difference of the ensemble averages was carried out to check the significance of this difference. Regions significant to a $95 \%$ (99\%) confidence level are shaded light (dark) gray on the plots.

A dipole appears in the composite corresponding to $\mathrm{PC}_{1}$ (Fig. 14a). A positive center over Portugal indicates that the increase in the precipitation associated with $\mathrm{PC}_{1}$ is also related with an increase in the baroclinic activity (Ulbrich et al. 1999). Also, a negative elongated region extending from Iceland, to Scandinavia, to a maximum (negative) on Russia and down to the Suez Canal over land is apparent. The baroclinic activity is reduced over these areas during high $\mathrm{PC}_{1}$ situations. This is a result traditionally associated with the NAO/Arctic Oscillation (NAO/AO) (Rogers 1997, Ulbrich et al. 1999).

The composite derived from $\mathrm{PC}_{2}$ (Fig. 14b) shows 3 centers of action. The first (negative) center is over the Azores, the second (positive) one extends from the British Isles to Italy and the third one (negative) is over Russia. The positive center implies an increase in the baroclinic activity over central Europe and the Mediterranean.

The main differences in standard deviation for $\mathrm{PC}_{3}{ }^{-}$ based composites are located east of France (Fig. 14c). This is also consistent with humidity inflow through the northern side of the western boundary associated with this PC and the precipitation pattern, which shows a maximum over France.

The one-point correlation maps were built taking as their base points the places where the standard deviation of geopotential height for each phase (cases where $-\sigma_{Z}>P_{1}>\sigma_{Z}$ ) is highest over the climatology of the standard deviation of $Z_{500}$ in the area. In other words, we computed the maps $\sigma_{Z}\left(\mathrm{PC}_{\mathrm{i}}+\right)-\bar{\sigma}_{Z}$ and $\sigma_{Z}\left(\mathrm{PC}_{\mathrm{i}}-\right)-\bar{\sigma}_{Z}$. In these maps, the highest values represent the areas where the changes in the standard deviation of filtered geopotential height for each composite are most intense. These points were selected as the base points for the one-point correlation maps. The maxima in Fig. 14 do not in general match the base points defined above, due to the asymmetry in the response of the standard deviation of filtered geopotential height to positive and negative phases of the PCs. Therefore, these maps represent the preferred pathways of baroclinic disturbances passing over the grid points with the highest standard deviation of $Z_{500}$ at these points during the extreme values of each PC. As already mentioned in Section 1, the resolution of the NCEP Reanalysis is too coarse to be able to detect subsynoptic-scale systems. Therefore, there may be a contribution to precipitation from these systems which is not being correctly taken into account in these one-point correlation maps.

Figs. 15, 16 \& 18 show how the synoptic disturbances propagate for positive phases of the different modes. These are plots of one-point correlation maps of the synoptic-scale filtered geopotential height field at $500 \mathrm{mb}$ level with all other grid points of the field at lagged times. The selected base point is indicated on each map with a circle.

During positive phases of $\mathrm{PC}_{1}$ (Fig. 15) there is an increase in the synoptic activity with a clear zonal propagation, but with no enhancement of the perturbations as they travel through the Mediterranean. The disturbances have their origin in the Atlantic storm track and decay over the Mediterranean. During negative phases (not shown) there is no evidence of structured synoptic activity over the Mediterranean.

During positive phases of $\mathrm{PC}_{2}$ (Fig. 16) the synoptic activity is increased over the Mediterranean and central Europe. The intensity of the perturbation increases through the Mediterranean, as can be seen from a comparison of the panels corresponding to Day +1 and Day -1. It is not possible to state with complete certainty why these disturbances grow over the Mediterranean. The hypothesis that the disturbances grow due to the latent heat release caused by the strong evaporation on the western Mediterranean Sea may be appealing. However, the analysis of the $Z_{500}-Z_{700}$ and $Z_{300}-Z_{500}$ thicknesses during $\mathrm{PC}_{2}$-based composites shows (Fig. 17) that the time-mean geopotential height field (equivalent barotropic) is consistent with the steering of the perturbations as seen by the one-point lagged correlation maps and that the meridional gradient of thickness is consistent with a strong vertical shear of the zonal wind during positive phases of $\mathrm{PC}_{2}$. This vertical wind shear is reduced during negative phases of $\mathrm{PC}_{2}$. Therefore, the statistical analysis in this paper is not able to discriminate whether the evaporation causes the increase in synoptic-scale disturbances in the atmosphere through the release of latent heat flux or whether the increase in evaporation is a consequence of the higher variance of the geopotential height (and, therefore, wind) field over the surface.

Structured and intense synoptic activity appears also in $\mathrm{PC}_{3}$ (Fig. 18). It comes from the Atlantic and affects 
a)

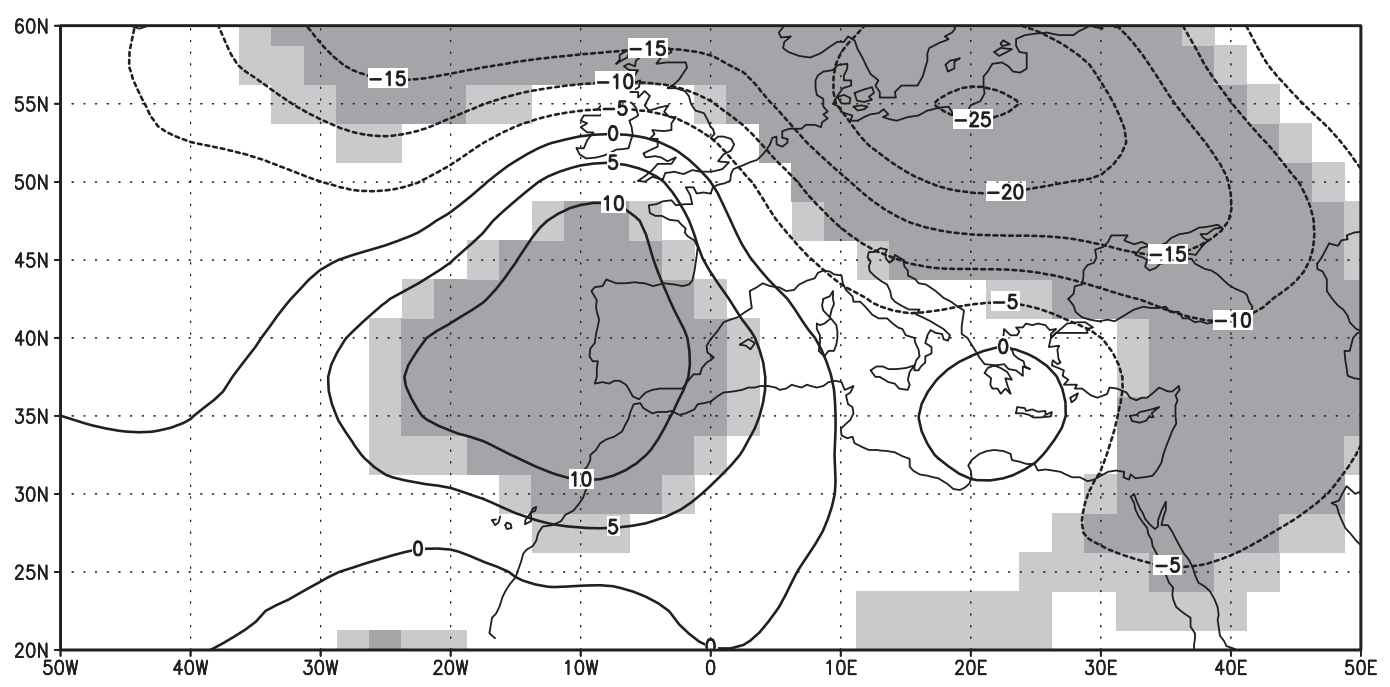

b)

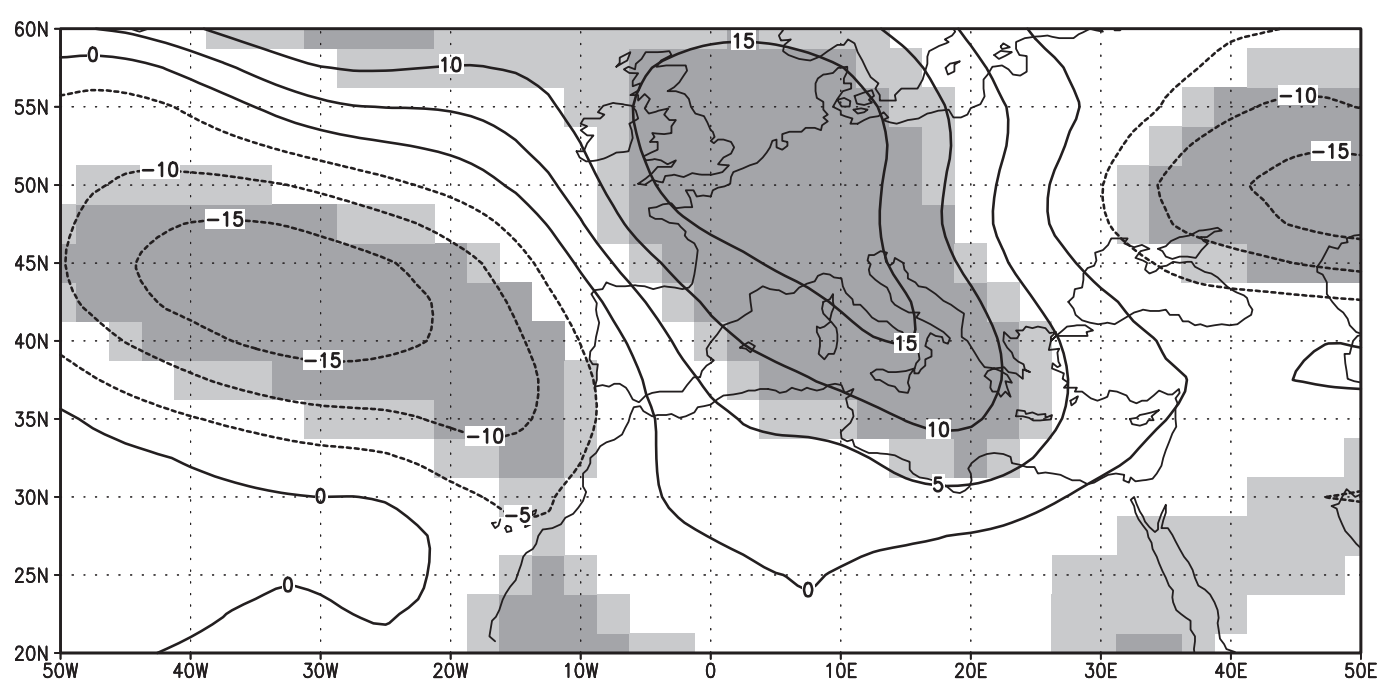

c)

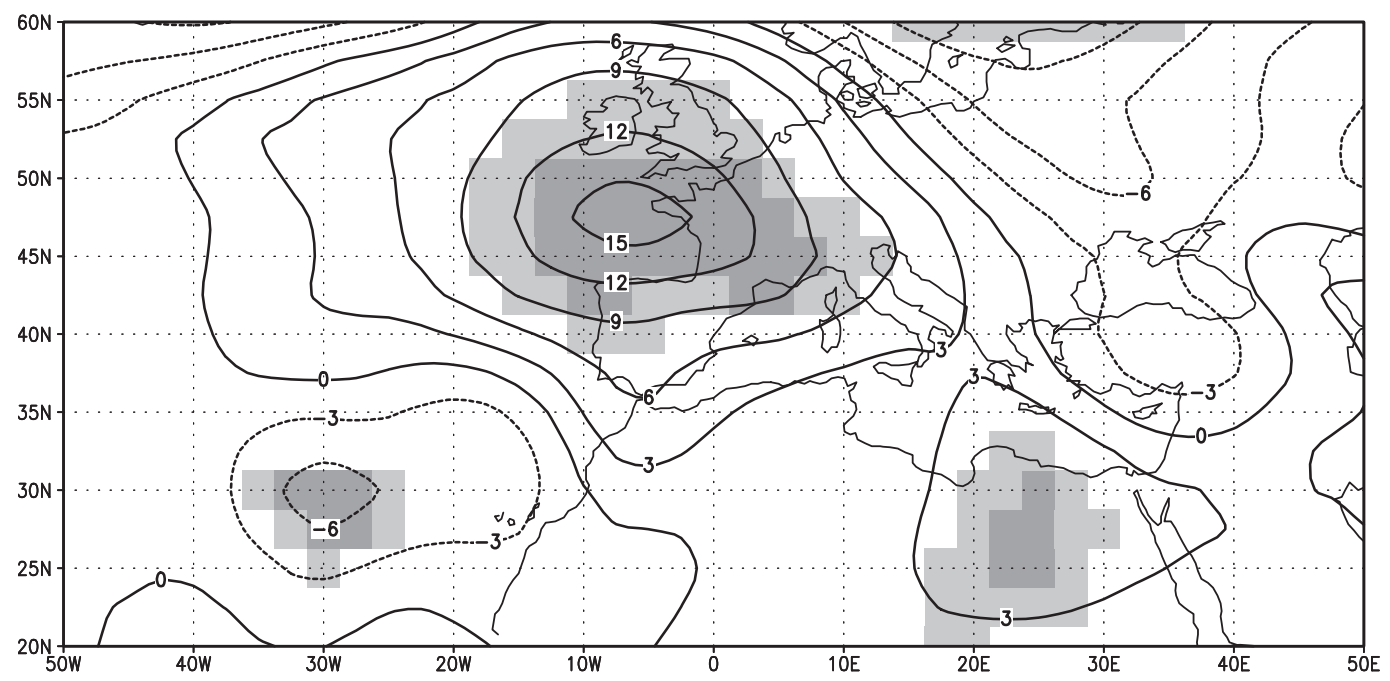

Fig. 14. Composites of standard deviation of filtered geopotential height (units: $\mathrm{m}$ ). Over light-grey-shaded regions the difference is significant to a $95 \%$ confidence level according to a 2-tailed $t$-test on the difference of means. Dark grey indicates $99 \%$ confidence level 
the northern side of the domain, as was already clear from the geopotential standard deviation composites (Fig. 14c). No clear enhancement of the perturbations takes place along the journey of the perturbations through the area. This time, the perturbations travel about $5^{\circ}(600 \mathrm{~km})$ to the north with respect to the extreme $\mathrm{PC}_{1}+$ case.

The previous results are consistent with significant vertical movements in the low levels of the troposphere. Fig. 19 shows that during high phases of
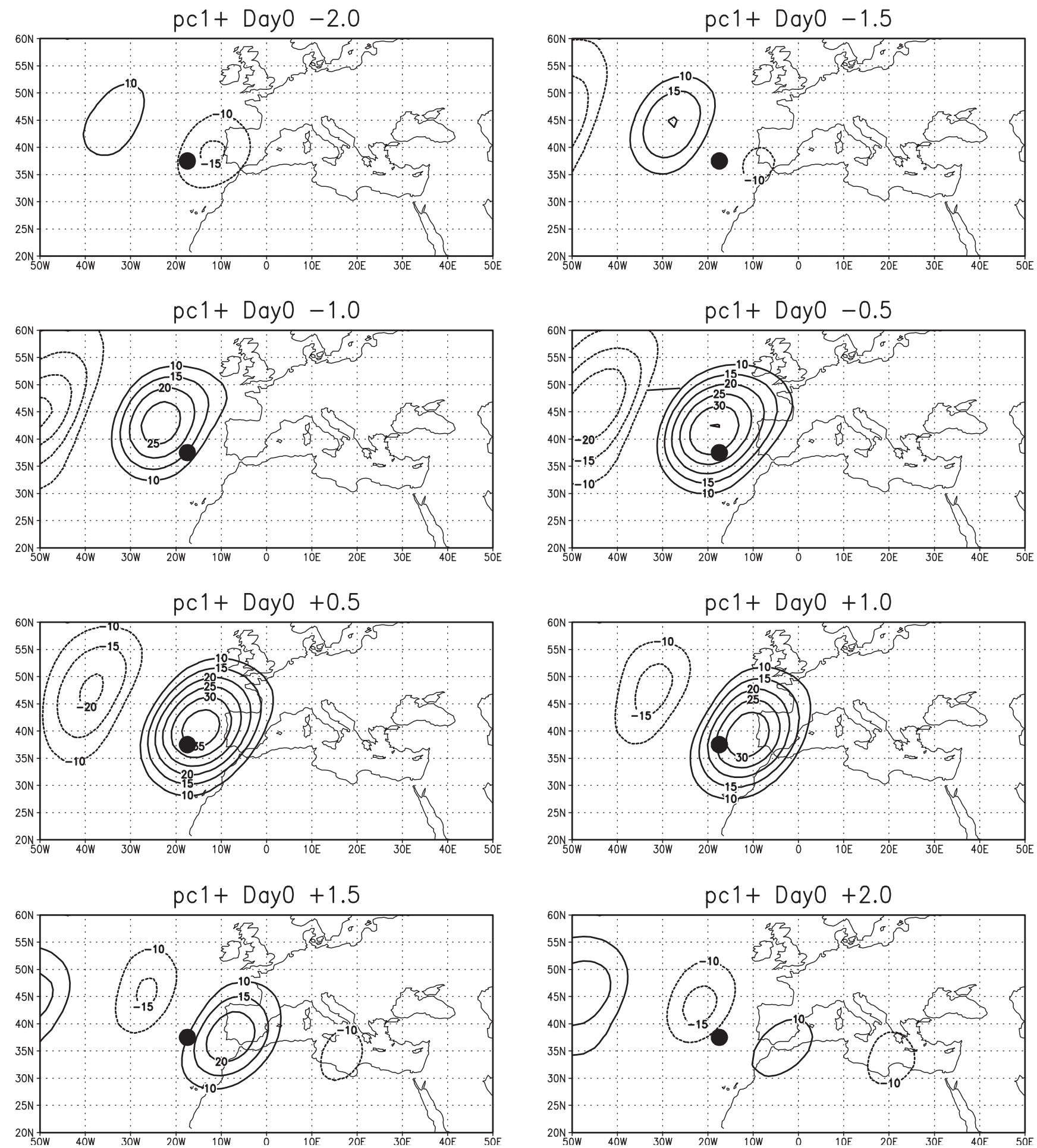

Fig. 15. Lagged one-point correlation maps for $\mathrm{PC}_{1}+$ extreme months. Base point: $-17.5^{\circ} \mathrm{W}, 37.5^{\circ} \mathrm{N}$ 
$\mathrm{PC}_{1}$, upward velocities occur over the Iberian Peninsula. $\mathrm{PC}_{2}$ is clearly linked to rising air over the eastern Mediterranean and subsidence over the Iberian Peninsula (Eshel \& Farrell 2000). Finally, $\mathrm{PC}_{3}$ shows signifi- cant vertical movements over the northern part of the domain, consistent with topographic forcing, as reflected by the clear relationship between the topography and the spatial structure of the EOF.
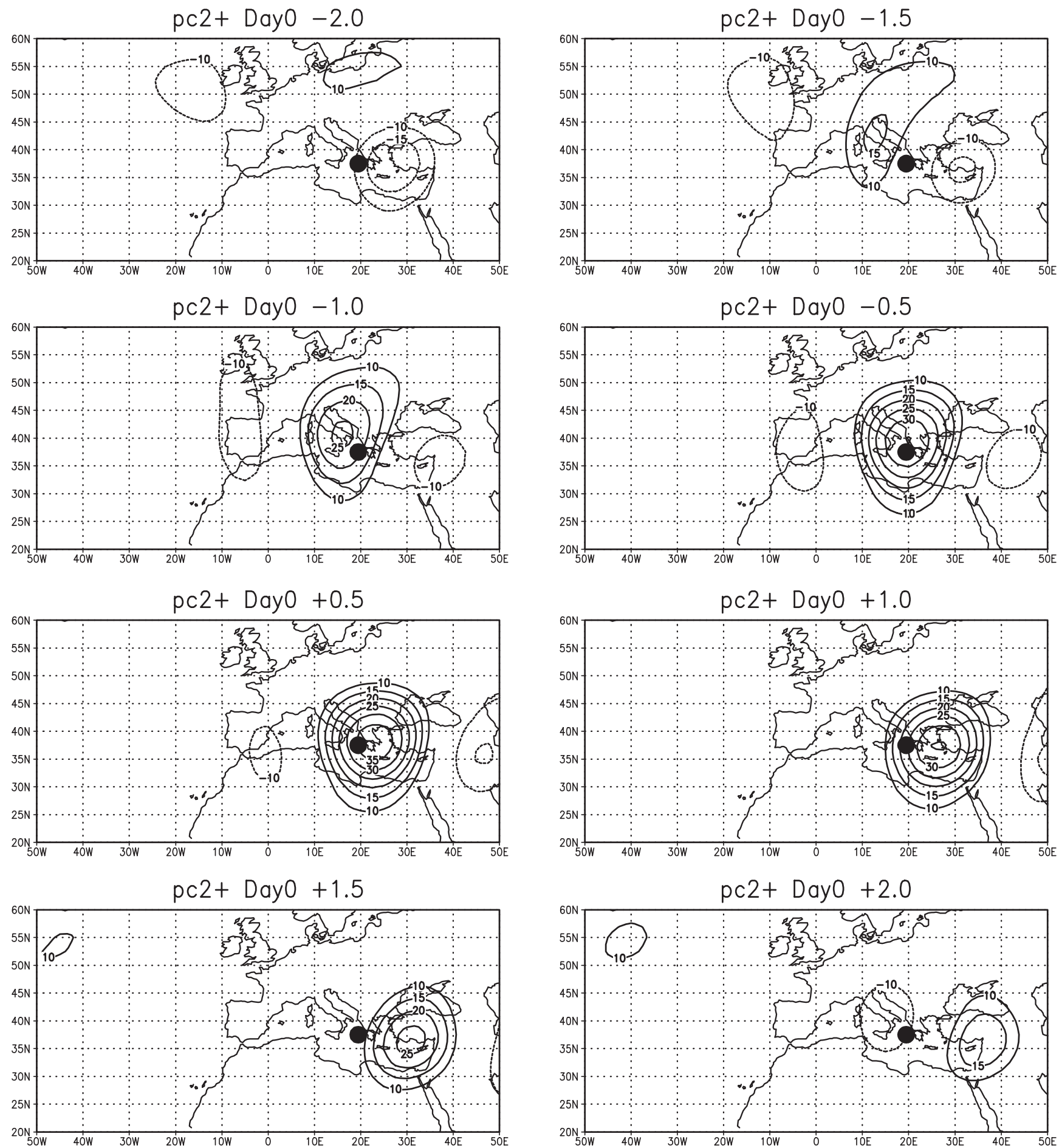

Fig. 16. Lagged one-point correlation maps for $\mathrm{PC}_{2}+$ extreme months. Base point: $20^{\circ} \mathrm{E}, 37.5^{\circ} \mathrm{N}$ 

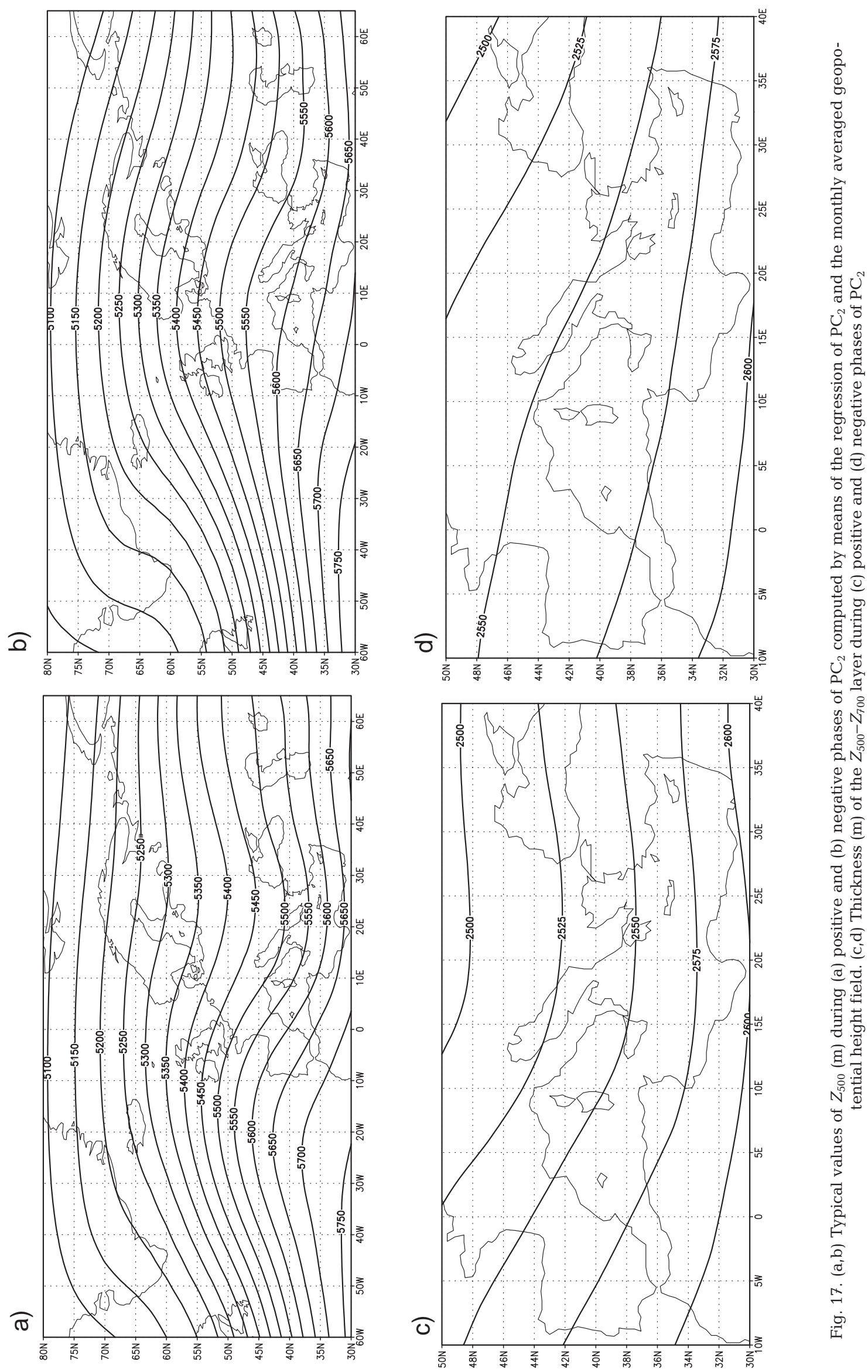


\section{CONCLUSIONS}

The analysis of 2 different instrumental data sets of wintertime precipitation over the Mediterranean basin yields 3 clearly separated and stable modes which are very similar in both data sets and which compare very favorably to the ones in a recent paper (Quadrelli et al. 2001) which used a third data set. These 3 modes explain $49 \%$ of the total precipitation variance. The leading mode resembles the well-known influence of
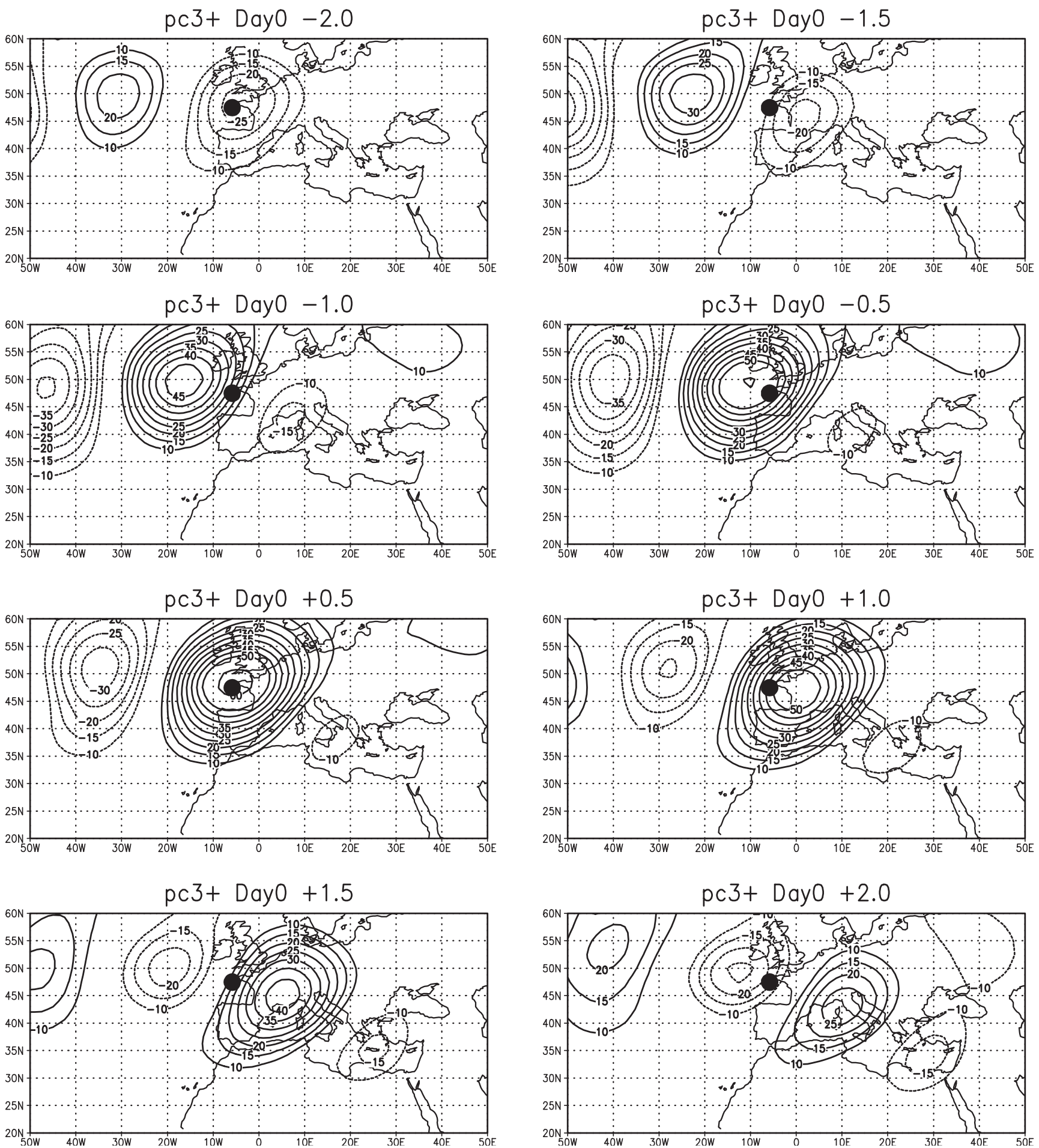

Fig. 18. Lagged one-point correlation maps for $\mathrm{PC}_{3}+$ extreme months. Base point: $5^{\circ} \mathrm{W}, 47.5^{\circ} \mathrm{N}$ 
a)

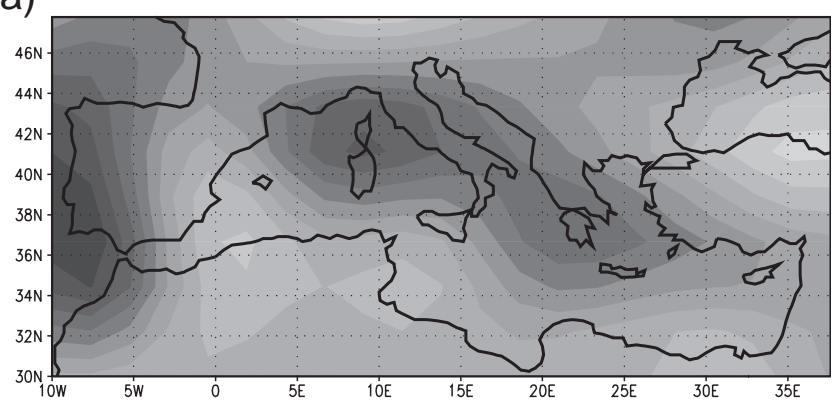

b)

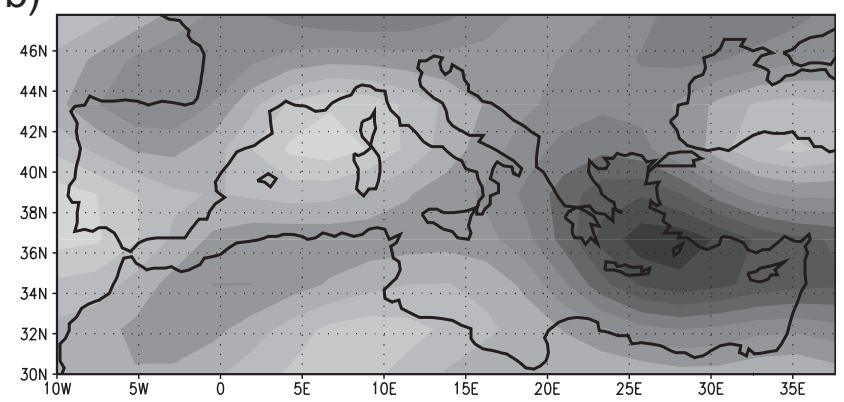

c)
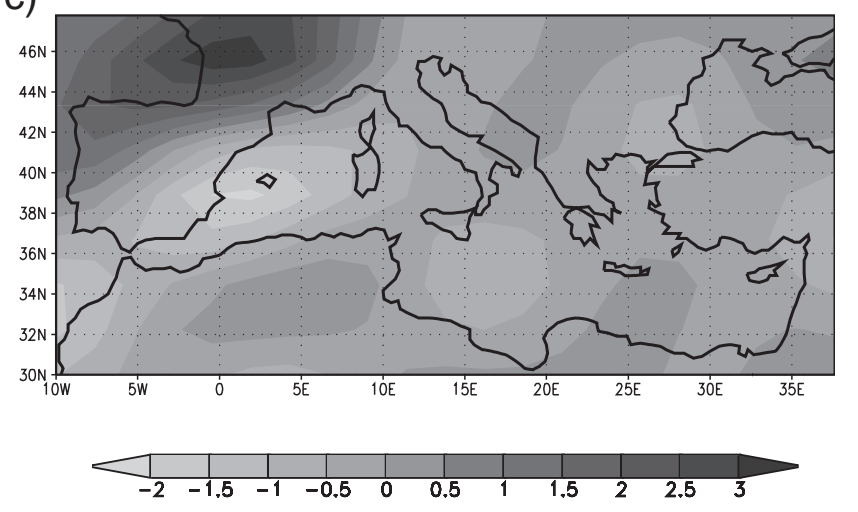

$\mathrm{mb} / \mathrm{sec} \times 100$ : positive, upwards

Fig. 19. Regression of the PCs with monthly values of $\omega$ $\left(\mathrm{hPa} \mathrm{s}^{-1}\right)$ at $850 \mathrm{hPa}$

the NAO on the precipitation over the area, the second one resembles a zonal dipole of precipitation between the western and eastern parts of the domain, and the third mode explains increased precipitation over the northern part of the domain.

The area shows a slight deficit (15 Pg) of moisture on average during the winter months. Moisture is transported into the area through the western boundary and leaves the region mainly through the eastern and southern boundaries.

The moisture transports during positive phases of the leading precipitation mode show an increase in the input of humidity through the western boundary and a slight increment of outflow through the northern boundary. Therefore, during positive phases of $\mathrm{PC}_{1}$, the area imports more humidity than on average.
The second mode is mainly internal to the Mediterranean basin. Moisture evaporates in the Gulf of Genoa and western Mediterranean and precipitates over Turkey and Greece, in the Eastern half of the domain. A clear intensification of baroclinic disturbances crossing the Mediterranean basin during positive phases of this mode is evident.

From the analysis performed, it is not possible to discriminate to what extent the release of latent heat flux constitutes the only source of energy accounting for this intensification. The time-mean geopotential height fields show that the mean equivalent barotropic field explains a clearly higher vertical wind shear during positive phases than during negative ones. Therefore, we are not able to identify the principal factor in the generation and intensification of baroclinic disturbances over the Mediterranean during positive phases of the second mode. It might be the release of latent heat flux which modifies the structure of the timemean geopotential height field, or it might be an excess of evaporation, because of increasing variability of meridional wind fields due to the higher standard deviation of the geopotential height and, accordingly, an increase in the turbulent transfer of water from the ocean to the atmosphere.

Finally, the third mode is a consequence of the intensification of humidity flux through the northern section of the western boundary and the reduction of moisture transport through the southernmost part of the western boundary. The spatial structure of the corresponding EOF clearly resembles the major topographic features of Europe. Moisture entering the domain through its northern section suffers from orographically forced ascent over the Alps, the Pyrennees and the Carpathians, which modulate the spatial distribution of precipitation. This mode appears simultaneously with an increase in baroclinic systems leaving the Atlantic storm track through the northern region of the domain, but there is no intensification of those systems as they propagate through the region. Instead, they decay as they propagate through the domain.

The evaluation of the moisture fluxes, despite some quantitative errors which may exist due to the poor horizontal and vertical resolutions of the Reanalyses has proved to be an effective tool. First, it has enabled the discussion of the origin of the moisture that precipitates over the different regions of the domain. Geopotential height fields may quantitatively indicate the way the humidity is advected by the time-mean circulations, but some processes, for example, evaporation or precipitation, are not accounted for by the geopotential height field alone. Second, the origin of the humidity allows us to show that the leading and third modes are closely related to the structure of atmospheric circulation surrounding the Mediterranean 
basin. Conversely, internal surface processes, such as evaporation in the Gulf of Genoa and the western Mediterranean, play a major role in the structure of the second mode of precipitation.

Despite the fact that this analysis was performed with one of the best sources of data of atmospheric moisture (NCEP Reanalyses), it suffers from some shortcomings. The horizontal and vertical resolutions of the Reanalysis are very coarse. This is a limiting factor in the search of a quantitatively balanced hydrologic cycle over an area such as the Mediterranean, with steep gradients of orography and continentality. There are too many regional circulations in the Mediterranean basin which are not well resolved by the Reanalyses. However, a more accurate analysis of the hydrological cycle will only be possible after the climatological community produces some very high (horizontal and vertical) resolution, long, homogeneous data sets such as the Reanalyses, which cover the whole Mediterranean basin. Only then will it be possible to analyze in detail the features identified in this paper.

Acknowledgements. Two of the authors (J.F. and J.S.) wish to acknowledge financial support by Euskal Meteorologi Zerbitzua - Servicio Vasco de Meteorología and GKSS. J.F. is also funded by the Departamento de Educación, Gobierno Vasco. J.F. and J.S. thank the GKSS Forschungszentrum for an enjoyable visit to Geesthacht during summer 2001. The data used in this work were downloaded from the Web servers of the Climate Prediction Center, the NCAR Climate and Global Dynamics Division, NASA Goddard Institute for Space Studies, the Carbon Dioxide Information Analysis Center at Oak Ridge National Laboratory, the CARDS server at the NCDC and the NCEP/NCAR Reanalysis Project. The gridded precipitation CRU data were supplied by the Climate Impacts LINK Project (UK Department of the Environment Contract EPG 1/1/16) on behalf of the Climatic Research Unit, University of East Anglia. Comments by 2 anonymous reviewers have significantly improved the initial version of this manuscript. The authors thank Dennis Bray for his help in the use of English.

\section{LITERATURE CITED}

Alpert P, Neeman BU, Shay-El Y (1990a) Climatological analysis of Mediterranean cyclones using ECMWF data. Tellus 42A:65-77

Alpert P, Neeman BU, Shay-El Y (1990b) Intermonthly variability of cyclone tracks in the Mediterranean. J Clim 3: $1474-1478$

Ambrizzi T, Hoskins B, Hsu HH (1995) Rossby wave propagation and teleconnection patterns in the Austral winter. J Atmos Sci 52:3661-3672

Berbery EH, Rasmusson EM (1999) Mississippi moisture budgets on regional scales. Mon Weather Rev 127:2654-2673

Berbery EH, Rasmusson EM, Mitchell KE (1996) Studies of North American continental-scale hydrology using Eta model forecast products. J Geophys Res 101:7305-7319

Chang EKM (1993) Downstream development of baroclinic waves as inferred from regression analysis. J Atmos Sci 50:2038-2053
Corte-Real J, Zhang X, Wang X (1995) Large-scale circulation regimes and surface climatic anomalies over the Mediterranean. Int J Climatol 15:1135-1150

Duchon CE (1979) Lanczos filtering in one and two dimensions. J Appl Meteorol 18:1016-1022

Eshel G, Farrell BF (2000) Mechanisms of Eastern Mediterranean rainfall variability. Bull Am Meteorol Soc 2: 3219-3232

Eskridge RE, Alduchov OA, Chernykh IV, Polansky AC, Doty SR (1996) A Comprehensive Aerological Reference Data Set (CARDS): Rough and systematic errors. Bull Am Meteorol Soc 76:1759-1775

González-Rouco JF, Heyen H, Zorita E, Valero F (2000) Agreement between observed rainfall trends and climate change simulations in the Southwest of Europe. J Clim 13: 3057-3065

González-Rouco JF, Jiménez JL, Quesada V, Valero F (2001) Quality control and homogeneity of precipitation data in the Southwest of Europe. J Clim 14:964-978

Gutowski Jr. WJ, Chen Y, Ötles Z (1997) Atmospheric water vapour transport in NCEP-NCAR Reanalyses: comparison with river discharge in the central United States. Bull Am Meteorol Soc 78:1957-1969

Higgins RW, Mo KC, Schubert SD (1996) The moisture budget of the central United States in spring as evaluated in the NCEP/NCAR and the NASA/DAO Reanalysis. Mon Weather Rev 124:939-963

Hulme M, Barrow EM, Arnell N, Harison PA, Downing TE, Johns TC (1999) Relative impacts of human-induced climate change and natural variability. Nature 397:688-691

Hurrell JW (1995) Decadal trends in the North Atlantic Oscillation: regional temperatures and precipitation. Science 269:676-679

Hurrell JW, van Loon H (1997) Decadal variations in climate associated with the North Atlantic Oscillation. Clim Change 36:301-326

Jones PD, Jónsson T, Wheeler D (1997) Extension to the North Atlantic Oscillation using early instrumental pressure observations from Gibraltar and south-west Iceland. Int J Climatol 17:1433-1450

Kalnay E, Kanamitsu M, Kistler R, Collins W and 18 others (1996) The NCEP/NCAR 40-year Reanalysis Project. Bull Am Meteorol Soc 77:437-471

Kutiel H, Maheras P, Guika S (1996) Circulation indices over the Mediterranean and Europe and their relationship with rainfall conditions across the Mediterranean. Theor Appl Climatol 54:125-138

Kutzbach JE (1967) Empirical eigenvectors of sea-level pressure, surface temperature and precipitation complexes over North America. J Appl Meteorol 6:791-802

Mariotti A, Struglia MV, Zeng N, Lau KM (2002) The hydrological cycle in the Mediterranean region and implications for the water budget of the Mediterranean Sea. J Clim 15: 1674-1690

Mo KC, Higgins RW (1996) Large-scale atmospheric moisture transport as evaluated in the NCEP/NCAR and the NASA/ DAO reanalyses. J Clim 9:1531-1545

Nakamura H, Tanaka M, Wallace JM (1987) Horizontal structure and energetics of northern hemisphere wintertime teleconnection patterns. J Atmos Sci 44:3377-3391

New M, Hulme M, Jones P (2000) Representing twentiethcentury space-time climate variability. Part II: Development of 1901-96 monthly grids of terrestrial surface climate. J Clim 13:2217-2238

North G, Bell T, Cahalan R, Moeng F (1982) Sampling errors in the estimation of empirical orthogonal functions. Mon Weather Rev 110:699-706 
Palutikof JP, Goodess CM, Guo X (1994) Climate change, potential evapotranspiration and moisture availability in the Mediterranean basin. Int J Climatol 14:853-869

Quadrelli R, Pavan V, Molteni F (2001) Wintertime variability of Mediterranean precipitation and its links with largescale circulation anomalies. Clim Dyn 17:457-466

Reddaway JM, Bigg GR (1996) Climatic change over the Mediterranean and links to the more general atmospheric circulation. Int J Climatol 16:651-661

Ribera P, García R, Díaz HF, Gimeno L, Hernández E (2000) Trends and interannual oscillations in the main sea-level pressure patterns over the Mediterranean, 1955-1990. Geophys Res Lett 27:1143-1146

Richman MB, Lamb PJ (1985) Climatic pattern analysis of three- and seven-day summer rainfall in the central United States: some methodological considerations and a regionalization. J Clim 24:1325-1343

Rodó X, Baert E, Comin FA (1997) Variations in seasonal rainfall in southern Europe during the present century: relationships with the North Atlantic Oscillation and the El Niño-Southern Oscillation. Clim Dyn 13:275-284

Rodríguez-Puebla C, Encinas AH, Nieto S, Garmendia J (1998) Spatial and temporal patterns of annual precipitation variability over the Iberian Peninsula. Int J Climatol 18:299-316

Rodwell MJ, Hoskins BJ (1996) Monsoons and the dynamics of deserts. Q J R Meteorol Soc 122:1385-1404

Rogers JC (1990) Patterns of low-frequency monthly sea level pressure variability (1899-1986) and associated wave cyclone frequencies. J Clim 3:1364-1379

Rogers JC (1997) North Atlantic storm track variability and its association to the North Atlantic Oscillation and climate variability of northern Europe. J Clim 10:1635-1647

Editorial responsibility: Hans von Storch, Geesthacht, Germany
Trenberth KE (1998) Atmospheric moisture residence times and cycling: implications for rainfall rates and climate change. Clim Change 39:667-694

Trenberth KE (1999) Atmospheric moisture recycling: role of advection and local evaporation. J Clim 12:1368-1381

Trenberth KE, Guillemot CJ (1995) Evaluation of the global atmospheric moisture budget as seen from analyses. J Clim 8:2255-2272

Trenberth KE, Guillemot CJ (1998) Evaluation of the atmospheric moisture and the hydrological cycle in the NCEP reanalysis. Clim Dyn 14:213-231

Trenberth KE, Stepaniak DP, Hurrell JW, Fiorino M (2001) Quality of reanalysis in the tropics. J Clim 14:1499-1510

Trigo IF, Davies TD, Bigg GR (1999) Objective climatology of cyclones in the Mediterranean region. J Clim 12: 1685-1696

Trigo IF, Davies TD, Bigg GR (2000) Decline in Mediterranean rainfall caused by weakening of Mediterranean cyclones. Geophys Res Lett 27:2913-2916

Ulbrich U, Cristoph M (1999) A shift of the NAO and increasing storm track activity over Europe due to anthropogenic greenhouse forcing. Clim Dyn 15:551-559

Ulbrich U, Christoph M, Pinto JG, Corte-Real J (1999) Dependence of winter precipitation over Portugal on NAO and baroclinic wave activity. Int J Climatol 19:379-390

Wallace JM, Gutzler DS (1981) Teleconnections in the geopotential height field during the Northern Hemisphere winter. Mon Weather Rev 109:784-812

Wallis TWR (1998) A subset of core stations from the Comprehensive Aerological Reference Dataset. J Clim 11:272-282

Zhang X, Wang X, Corte-Real J (1997) On the relationships between daily circulation patterns and precipitation in Portugal. J Geophys Res 102:13495-13507

Submitted: December 10, 2001; Accepted: December 13, 2002 Proofs received from author(s): March 11, 2003 